\title{
Fractal asperities, invasion of barriers, and interplate earthquakes
}

\author{
Tetsuzo Seno \\ Earthquake Research Institute, University of Tokyo, Tokyo 113-0032, Japan \\ (Received June 23, 2003; Revised December 2, 2003; Accepted December 17, 2003)
}

\begin{abstract}
I present a model to explain seismicity variations along consuming and transform fault plate boundaries. The basic assumptions of the model are: (1) plate boundary fault zones consist of asperities and barriers, which are defined as having negative and positive $a-b$ values, respectively, of rate and state dependent friction laws, (2) circular-shaped asperities are distributed in a fractal manner, such that an asperity contains smaller asperities inside, (3) pore fluid pressure can be elevated almost to the lithostatic only in barriers (called invasion of barriers), and (4) a region whose barriers are invaded can rupture as an earthquake. Based on these assumptions, I re-estimate fault areas of interplate earthquakes along the San Andreas and near Japan. The derived relation between fault area and seismic moment for these earthquakes determines the fractal dimension of asperities to be 1.4, and nine smaller asperities are contained in a larger one of which the radius is 4.8 times those of the smaller ones. Various modes of invasion of barriers with a fractal distribution of asperities can explain the seismological phenomena such as variations of seismic coupling along plate boundaries, two types of earthquake families, and co-existence of the Gutenberg-Richter's law and characteristic repeating earthquakes.
\end{abstract}

Key words: Interplate earthquakes, asperity, barrier, pore pressure, San Andreas, earthquake family.

\section{Introduction}

There have been efforts to understand variations of seismic coupling along subduction zones in terms of factors such as age of the subducting plate (Ruff and Kanamori, 1980; Peterson and Seno, 1984; Kanamori, 1986; Pacheco et al., 1993), convergence rate (Ruff and Kanamori, 1980; Peterson and Seno, 1984; Kanamori, 1986; Pacheco et al., 1993), motion of the upper plate (Uyeda and Kanamori, 1979; Peterson and Seno, 1984; Scholz and Campos, 1995), amount of subducted sediments (Ruff, 1989), thermal regime of the thrust zone (Shimamoto et al., 1993; Hyndman et al., 1997; Oleskevich et al., 1999), and combinations of these. These are partly successful for explaining gross features such as regional variations in coupling width, maximum size of earthquakes, and seismic coupling ratio (seismic slip/convergence rate).

However, variations of subduction zone seismicity seem to be much more complex. For example, along the Japan Trench, large to great earthquakes, such as the 1968 Tokachioki $\left(M_{w} 8.2\right)$ and the 1994 Sanriku-haruka-oki $\left(M_{w} 7.7\right)$ earthquakes, occur in the northern segment, but they are very rare in the southern segment (Utsu, 1974; Seno and Eguchi, 1983; Kawakatsu and Seno, 1983). There seems to be no simple way to explain this variation in terms of the general tectonic factors cited above, because the subducting Pacific plate and the overriding Okhotsk plate (Seno et al., 1996) are similar along the entire Japan Trench. Another example is the difference in seismicity between Mexico, southwest Japan, and Cascadia, where young oceanic plates of similar ages $(\sim 10 \mathrm{Ma})$ are being subducted. The recurrence in-

Copy right(C) The Society of Geomagnetism and Earth, Planetary and Space Sciences (SGEPSS); The Seismological Society of Japan; The Volcanological Society of Japan; The Geodetic Society of Japan; The Japanese Society for Planetary Sciences. tervals of great earthquakes vary among these arcs by one order of magnitude from 50 years in Mexico to 500 years in Cascadia, with southwest Japan in between (Kostoglodov and Ponce, 1994; Ando, 1975; Atwater and Hemphill-Haley, 1997). It is also very difficult to explain this variation in terms of general tectonic factors.

It has also been known that there is a similar variation in seismicity or seismic coupling along the San Andreas fault, such that some regions produce great earthquakes but others are mostly aseismic and creeping (e.g., Scholz et al., 1969; Wallace, 1970). It also seems to be difficult to explain this (Irwin and Barnes, 1975).

Another way to explain these regional variations in seismicity along plate boundaries, rather than relying on general tectonic factors, is to introduce asperities whose sizes vary from one place to another (Lay and Kanamori, 1981; Lay et al., 1982). This asperity model claims that asperity size is very large in southern Chile where great earthquakes recur, while it is very small in the Marianas where only minor earthquakes occur (Fig. 1(a)). Although the asperity size in each segment of plate boundaries may be inferred from analyses of seismic waveforms, it is further necessary to explain how it varies from region to region in terms of general tectonic factors.

In this paper, I explore another way to understand variations in seismic coupling along plate boundaries and propose a model that is not related to asperity size, but to other factors, i.e., fractal geometry of asperities and behavior of fluids in plate boundary fault zones. Dieterich and Kilgore (1996) showed that contact areas between two rock specimens have a fractal distribution with fractal dimensions between 1.0 and 2.7. Because the seafloor topography is fractal (Mareschal, 1989), it is natural to expect that subduction zone thrusts 


\section{(a) Asperity model}
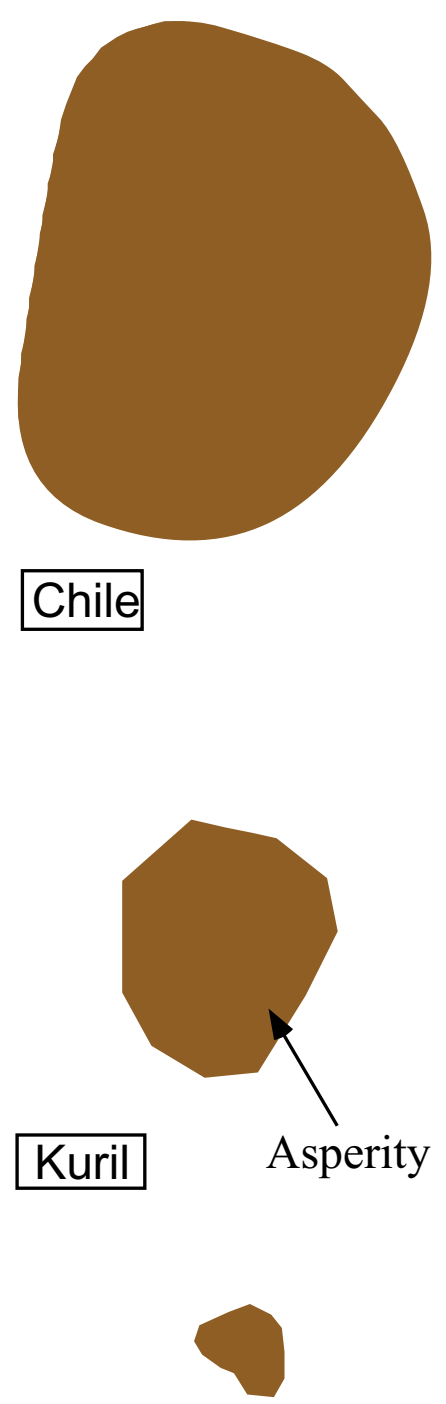

\section{Mariana}

\section{(b) Fractal asperity/invasion of barriers model}
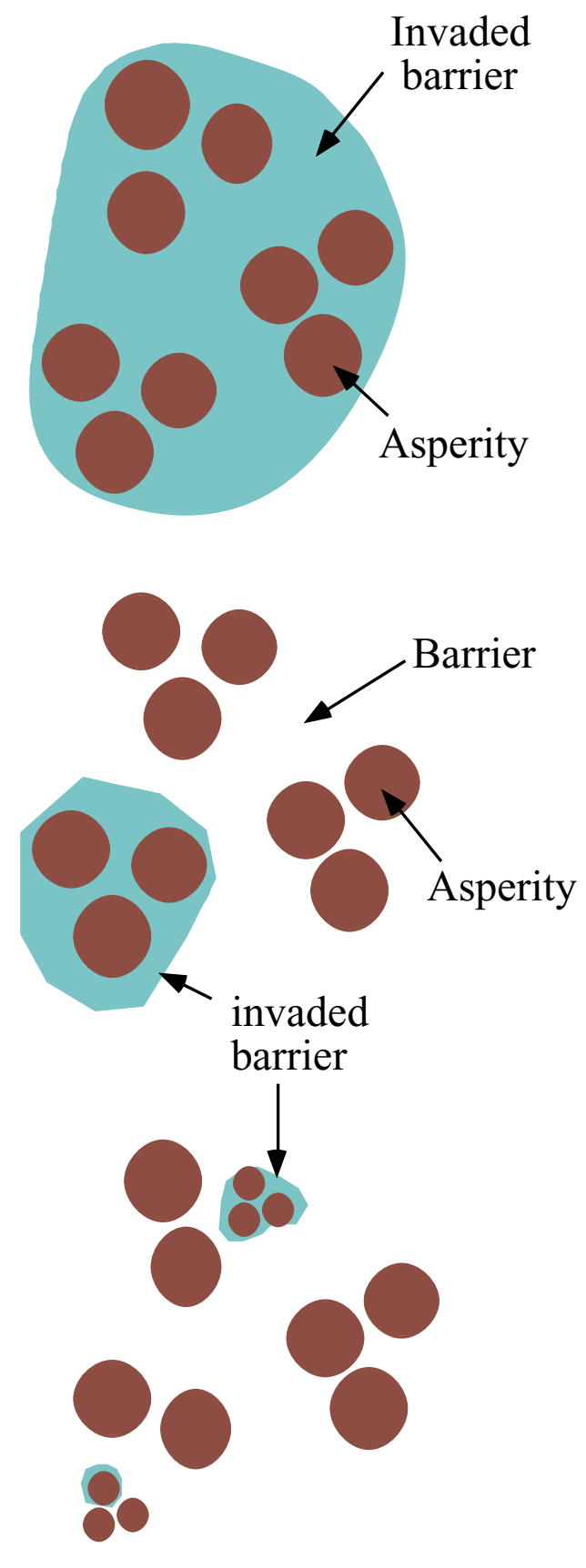

Fig. 1. Asperity model (Lay and Kanamori, 1981; Lay et al., 1982). Asperity size changes from place to place, which explains regional variations of seismic coupling. (b) Fractal asperity/invasion of barriers model in this study. Asperities are surrounded by barriers with stable sliding frictional properties. The shaded area indicates the region where barriers are invaded by elevated pore fluid pressure; this region can break as an earthquake. Asperities are assumed to be distributed in a fractal manner. Variations of seismicity along plate boundaries can be explained by the various modes of invasion of barriers.

have fractal contact areas, provided that bumps in topography such as seamounts become asperities (Cloos, 1992). An asperity is introduced here as a part with an unstable sliding frictional property, having a negative $a-b$ value in the rate and state dependent friction laws (Dieterich, 1979; Ruina, 1983; Scholz, 1990, p. 320). On the other hand, the barrier introduced here is an absorbing barrier with a stable slid- ing frictional property, having a positive $a-b$ value. I then propose that asperities are in a fractal distribution such that an asperity contains smaller asperities inside, surrounded by barriers.

Fractal distribution of asperities was already introduced in the hierarchy model of earthquake sources (Fukao and Furumoto, 1985; Kikuchi, 2000). They tried to explain the 
magnitude gaps between the mainshock and sub-events, and between the mainshock and the largest aftershocks, precursory slow rupture before the main rupture, the Gutenberg Richter's law, and short-period components of seismograms. The fractal dimension of asperities in their model is 2 . The model in this study differs from their model in that the fractal dimension of asperities is less than 2, i.e., that barrier portions are contained in the source. Further, frictional properties of the barrier portions are allowed to be time-dependent.

In the San Andreas, repeating microearthquakes, some smaller earthquakes, and the $M \sim 6$ Parkfield earthquakes have regular recurrence time intervals (Nadeau et al., 1995; Ellsworth and Dietz, 1990; Bakun and McEvilly, 1984). Nadeau and Johnson (1998) estimated the fault areas of these earthquakes assuming that their moment release rate is comparable to tectonic loading rate. The resulting relation between fault area and seismic moment implied a fractal distribution of asperities, such as the stress drop becomes smaller as the fault area becomes larger (Sammis et al., 1999). I strengthen and revise their scaling relation by augmenting the data including fault areas and seismic moments of larger earthquakes along the San Andreas and near Japan. The revised scaling relation shows that the stress drop of the smallest repeating eartuquakes in the Parkfield is $\sim 340 \mathrm{MPa}$ and the strength of the asperities contained in them is $\sim 1.4 \mathrm{GPa}$. The latter coincides with the strength of intact granitic rock (Savage et al., 1996; Sammis et al., 1999).

It has been recognized that fluids may play important roles in earthquake occurrence along plate boundaries. Elevated pore fluid pressure in fault zones would be one of the most plausible factors to help to reduce rock strength by reducing effective normal stresses $\sigma_{n}^{*}=\sigma_{n}-p$, where $p$ is the pore fluid pressure and $\sigma_{n}$ is the normal stress (Hubbert and Rubey, 1959; Sibson, 1981; Hickman et al., 1995). In the 1990's, various models that explain earthquake occurrence incorporating the roles of superhydrostatic pore fluid pressure in fault zones, in association with fluid infiltration, sealing, compaction, dilation, and diffusion, have been proposed (Sibson, 1992; Rice, 1992; Blanpied et al., 1992; Sleep and Blanpied, 1992; Byerlee, 1993; Sleep, 1995; Lockner and Byerlee, 1995; Johnson and McEvilly, 1995). The compaction of pore in the fault gouge by stressing elevates the pore pressure, which reduces the strength of the fault, and faulting occurs when the ambient tectonic stress reaches the strength. The pore pressure is then reduced by the dilation of the fault gouge due to faulting, and the process repeats. This fault-valve model and its variation are partly motivated by the requisite that the effective shear strength along the San Andreas fault has to be less than ca. $20 \mathrm{MPa}$ at seismogenic depths, to be consistent with the observed heat flow anomalies (Lachenbruch and Sass (1992); see also Mount and Suppe (1987) and Zoback et al. (1987) for the low strength requirement). This strength is smaller by an order of magnitude than that expected from the Coulomb-Navier failure criterion at a depth of $7 \mathrm{~km}$.

Similarly, in subduction zones, a reduction of shear strength at thrust zones seems to be required for earthquakes to occur in fault zones deeper than approximately $10 \mathrm{~km}$ where the lithostatic pressure exceeds ca. $300 \mathrm{MPa}$, given the magnitude of tectonic stresses is on the order of $100 \mathrm{MPa}$ or less (Fleitout, 1991; Parsons and Richter, 1980; Wiens and Stein, 1985). At a depth of $30 \mathrm{~km}, 80 \%$ or more of the lithostatic stress must be sustained by pore fluid pressure for earthquakes to occur, assuming the frictional constant of 0.6. Consistently, fault normal $P$-axes have been found for earthquakes within plates in the vicinity of the thrust zone of northern Honshu (Hurukawa and Imoto, 1992; Magee and Zoback, 1993), which may imply that strength reduction is operating there due to elevated pore fluid pressure.

However, there is a serious difficulty in the models of this sort. Because the critical stiffness of the fault zone is proportional to the effective stress $\sigma_{n}^{*}$ (e.g., Scholz, 1990), pore fluid pressure close to the lithostatic makes the critical stiffness very small. Given a finite stiffness of the fault, this generally results in stable sliding on the fault (See also Segall and Rice, 1995). In the model presented here, in contrast to the previous models, I assume that only a part called "barrier" can be effectively affected by pore fluid pressure (Fig. 1(b)), to avoid the overall stabilization of the fault. When any barrier portion has pore fluid pressure elevated almost to the lithostatic, I call the barrier invaded. A corollary is that seismic rupture can initiate only when an asperity breaks within invaded barriers (Figs. 1(b) and 2). This is because, when an asperity breaks surrounded by invaded barriers, faulting would propagate within these barriers with almost no friction, and further induce breakage of nearby asperities. Instead, if barriers surrounding the asperity are not invaded, the propagation of faulting would be prohibited by the barriers (Tse and Rice, 1986; Kato and Hirasawa, 1999). This leads to the idea that a size of an earthquake represents the spatial extent of invasion of barriers, not the size of an asperity (Fig. 1(b)).

I first describe model assumptions and derive scaling relations for failures between different sizes of asperities. I apply the notion of invasion of barriers to interplate earthquakes along the San Andreas and the subduction zones near Japan, and re-estimate their fault areas. I then determine the fractal geometry of asperities from the relation between fault area and seismic moment, and the stress drop of the smallest earthquakes in the San Andreas and the strength of the smallest asperities inside them (called unit asperities hereinafter). Finally, I show in the discussion section that the present model can explain some enigmatic features of seismicity along plate boundaries, such as variations of earthquake size within a short segment, two types of earthquake families, and co-existence of characteristic repeating earthquakes and the Gutenberg-Richter's law.

\section{Model}

The model presented here concerns geometrical distribution of asperities and temporal changes of the frictional property of barriers in fault zones along convergent or transform fault plate boundaries. The basic assumptions of the model are:

(1) A plate boundary fault zone consists of asperities and barriers, which are defined in the previous section. For simplicity, I include conditionally stable areas that have negative but small $\mathrm{a}-\mathrm{b}$ values (the weakly seismic areas of Boatwright and Cocco (1996)) in barriers. Note that barriers defined here are different from the high cohesive strength ar- 


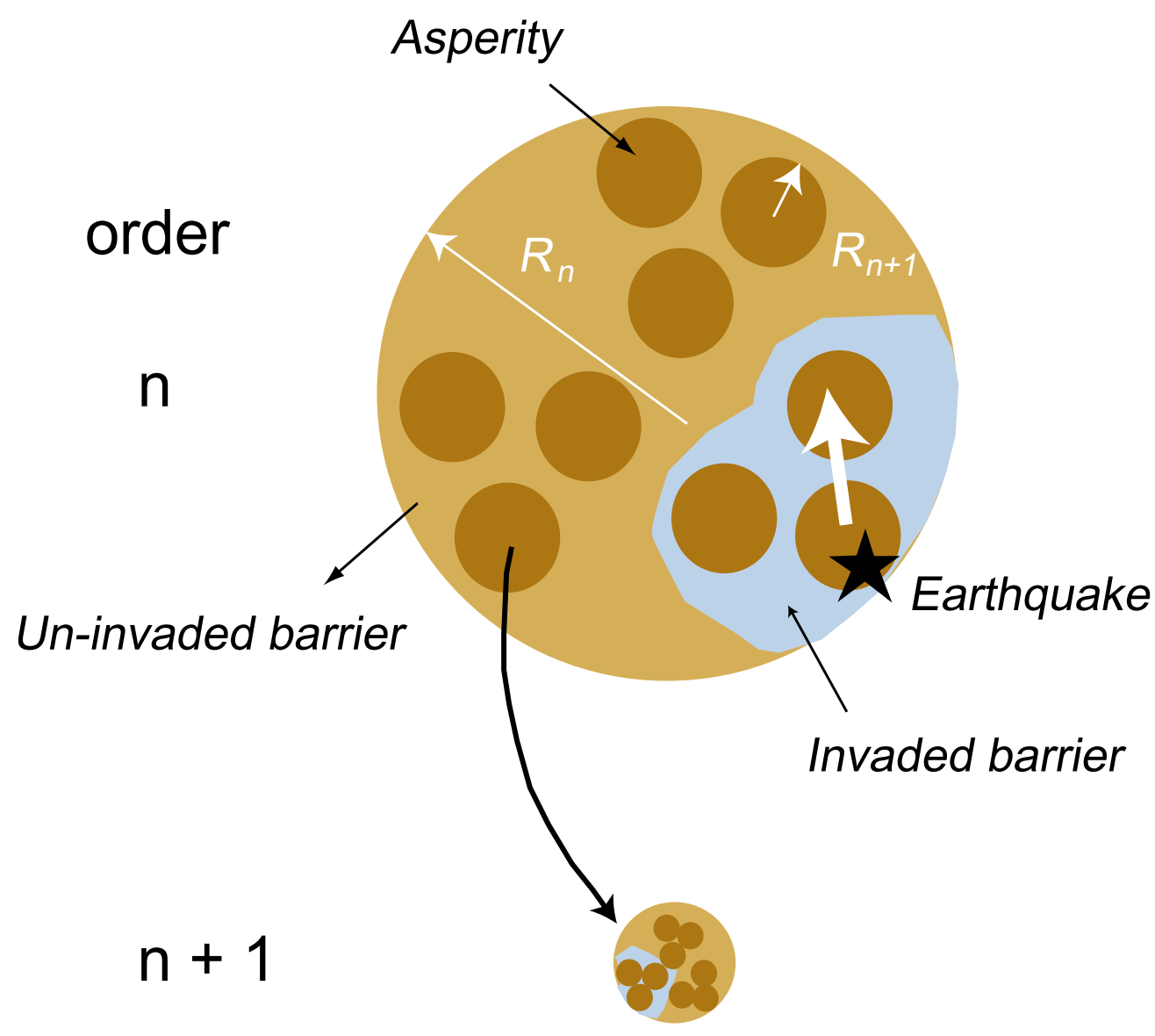

Fig. 2. Fractal geometry of asperities. An asperity is assumed to have a circular shape. An order $n$ asperity contains a number of $N_{a}$ order $n+1$ asperities. The ratio in radius between order $n$ and order $n+1$ asperities, i.e., $R_{n} / R_{n+1}$, is $\lambda . N_{a}$ and $\lambda$ determine the fractal geometry of asperities. The region where barriers are invaded is lightly shaded and can produce an earthquake.

eas (hard barriers) originally defined by Das and Aki (1977) and Aki (1979). Because barriers have stable sliding frictional properties, they release shear stresses continually, and transfer them into asperities. I then assume that barriers carry stresses only at a marginal level generally.

(2) Asperities are distributed in fractal and their geometry does not vary along plate boundaries. For simplicity, I assume that each asperity has a circular shape, and introduce the "order" of an asperity such that an order 0 asperity is the largest, and within an order $n$ asperity, a number of $N_{a}$ order $n+1$ asperities are contained, whose radius is $1 / \lambda$ of that of an order $n$ asperity (Fig. 2). I further assume that $N_{a}$ and $\lambda$ are not functions of $n$.

(3) Barriers may change their stable sliding frictional property to nearly zero friction due to an elevation of pore fluid pressure almost to the lithostatic (invasion of barriers). There is extensive evidence that pore fluid pressure in fault zones can be elevated to superhydrostatic or nearly lithostatic (see Hickman et al. (1995) for review). For the decollement in the Cascadia subduction zone, Tobin et al. (1994) indicated that observed waveforms of negative polarity reflections imply a pore fluid pressure amounting to 86 to $98 \%$ of the lithostatic. For faults such as the San Andreas, Byerlee (1993) discussed possibility of the formation of highpressured compartments by sealing due to mineral deposition. Therefore, fault zones may, in some cases, be invaded by fluids. I assume here that only barriers are affected by pore fluids significantly, and asperities are not. Because each asperity consists of barriers and smaller asperities, it may be invaded further. Then only the unit asperities can escape being invaded. This assumption is made to avoid the overall stabilizing effect of the high pore fluid pressure on a fault zone as stated before.

(4) Only the region whose barriers are invaded can rupture as an earthquake in association with breakage of asperities contained (Figs. 1 and 2). Figure 2 illustrates a situation that part of barriers within an order $n$ asperity is invaded, containing some order $n+1$ asperities inside. In this case, I assume that any order $n+1$ asperity within the order $n$ asperity can break seismically when a shear stress larger than its strength is applied. If invaded barriers surround order $n+1$ asperities, a breakage of one of the asperities loads nearby asperities instantaneously, and rupture may propagate through the asperities. This mode of rupture is called "earthquake mode". I define the "order" of this earthquake to be $n$. The degree of this earthquake is defined by the number of order $n+1$ asperities within the rupture zone (Fig. 3). Then, the maximum degree of an earthquake is $N_{a}$ and the minimum is 1 . Instead, if un-invaded barriers surround order $n+1$ asperities, these barriers, even if loaded suddenly with a breakage of one of the asperities, do not slip instantaneously, but slip slowly to relieve the load (Tse and Rice, 1986; Kato and Hirasawa, 
1999; Boatwright and Cocco, 1996). The barriers transfer stresses ultimately to nearby asperities and may induce seismic rupture of another asperity. This mode of rupture within the order $n$ asperity is called "slow failure mode".

\section{Scaling laws between orders}

In this section, I introduce scaling relations of various fault parameters for failures of asperities between order $n$ and order $n+1$. Areas, $A_{n}$ and $A_{n+1}$, have the relation

$$
A_{n+1}=\left(1 / \lambda^{2}\right) A_{n}
$$

Because I assume that barriers do not carry significant stresses, shear strength $\tau_{n}$ over an order $n$ asperity is related to $\tau_{n+1}$ over an order $n+1$ asperity by a force balance as

$$
N_{a} \tau_{n+1} A_{n+1}=\tau_{n} A_{n},
$$

which leads to

$$
\tau_{n+1}=\left(\lambda^{2} / N_{a}\right) \tau_{n}
$$

I assume that strength $\tau_{n}$ is totally relieved as a stress drop when an order $n$ asperity fails slowly. Letting the displacement associated with the slow failure of an order $n$ asperity be $u_{n}$, and the stress drop associated with this failure be proportional to $u_{n} / A_{n}^{0.5}$, Equation (3) leads to

$$
u_{n+1} / A_{n+1}^{0.5}=\left(\lambda^{2} / N_{a}\right) u_{n} / A_{n}^{0.5} .
$$

With Eq. (1), this further leads to

$$
u_{n+1}=\left(\lambda / N_{a}\right) u_{n}
$$

Finally, moment $M_{\text {on }}$ associated with the slow failure is related to $u_{n}$ and $A_{n}$ by $M_{o n}=\mu u_{n} A_{n}$, where $\mu$ is the rigidity. I then obtain from Eqs. (1) and (5)

$$
M_{o n+1}=M_{o n} /\left(\lambda N_{a}\right) .
$$

Following the definition of a fractal dimension $D$ (e.g., Turcotte (1989)), a number of objects, $N$, having a characteristic size $R$ is related to $R$ as

$$
N \propto R^{-D}
$$

From the definition of $N_{a}$ and $\lambda$ between order $n$ and $n+1$ asperities, I obtain, using Eq. (7),

$$
N_{a}=(1 / \lambda)^{-D}
$$

which gives

$$
D=\log \left(N_{a}\right) / \log (\lambda) .
$$

In the next section, I determine the values of $\lambda, D$, and $N_{a}$ from observational data. Scaling relations for earthquakes are slightly different from those of the slow failure above. When a degree $i$ order $n$ earthquake occurs as breakage of isolated asperities within an invaded barrier region (Fig. 3), broken order $n+1$ asperities produce isolated stress drops (Fig. 4(a)). Only the motion over the asperities contributes to the moment, even if any motion occurs over the invaded barriers, since no strain eneary is stored across the invaded barriers. These instantaneous stress drops gradually evolve into the stress drop associated with the slow failure (Fig. 4(b))

\section{Degree $\mathrm{Na}_{\mathrm{a}}$}

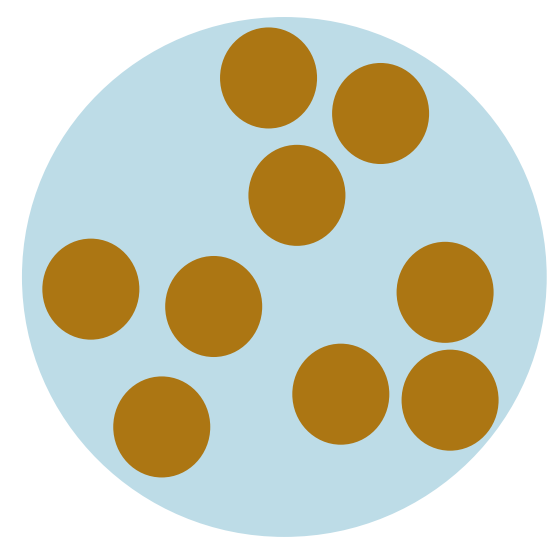

\section{Degree 3}

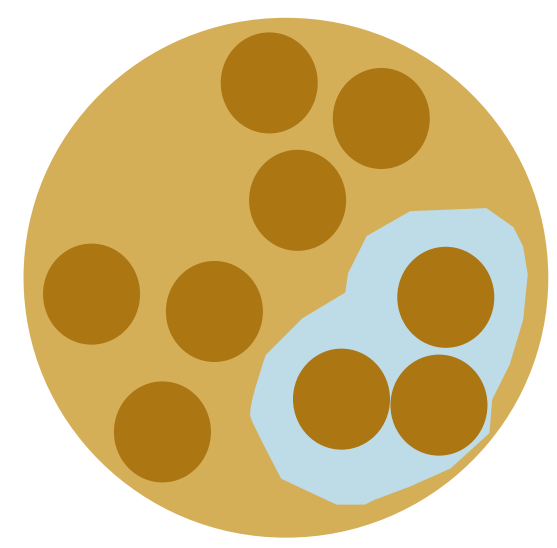

\section{Degree 1}

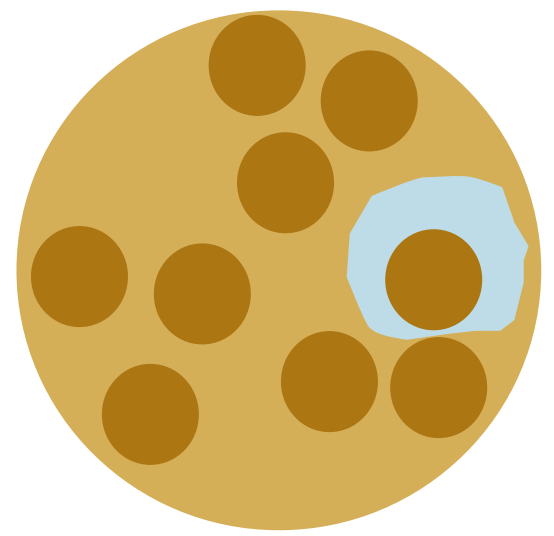

Fig. 3. Degree of an earthquake is defined by the number of order $n+1$ asperities included in the invaded barriers which is a fraction of an order $n$ asperity.

after some time. Then moment $M_{o n}^{i}$ and fault area $A_{n}^{i}$ of a degree $i$ order $n$ earthquake are

$$
M_{o n}^{i}=i M_{o n+1}
$$




\section{(a) Earthquake mode}

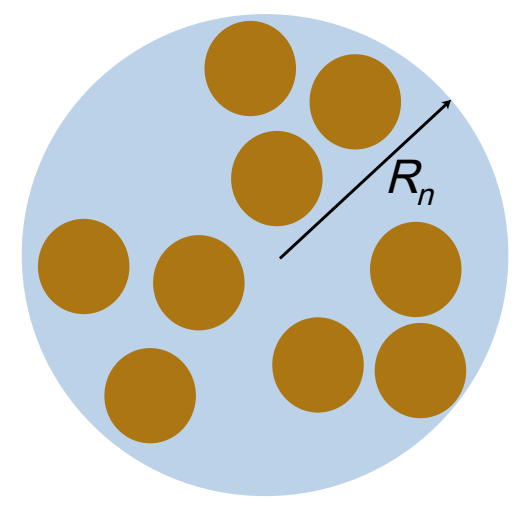

(b) Slow failure mode

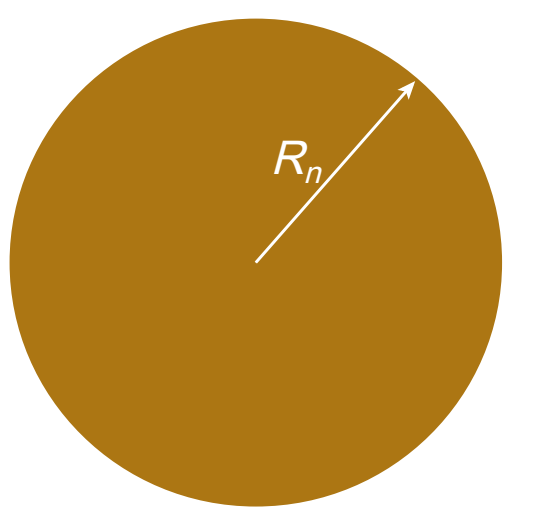

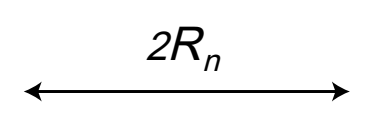
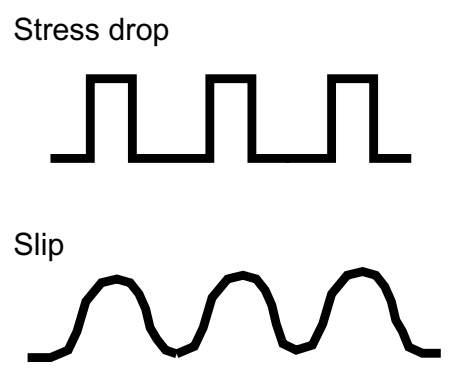

Stress drop
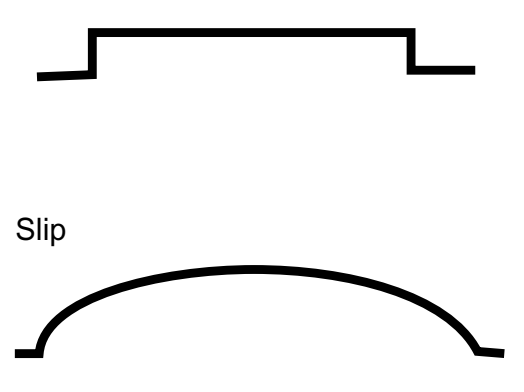

Fig. 4. Two types of failure mode of asperities. (a) In earthquake mode, stress drops are discrete and slip is localized. The total moment is $i M_{\text {on }+1}$ for a degree $i$ earthquake. (b) In the slow failure mode, the average strength is relieved as a stress drop over the whole asperity. The total moment in this case is $M_{o n}$, which is larger by a factor $\lambda$ than that of a degree $N_{a}$ earthquake.

and

$$
A_{n}^{i}=\left(i / N_{a}\right) A_{n},
$$

respectively. The total moment of a degree $N_{a}$ order $n$ earthquake is $N_{a} M_{o n+1}$ which equals $M_{o n} / \lambda$ from Eq. (6). The average stress drop of a degree $N_{a}$ order $n$ earthquake is then smaller by the same factor than that of the slow failure. This distinction between an earthquake and slow failure becomes important when I interpret the fault areas and seismic moments of repeating earthquakes in the San Andreas obtained by Nadeau and Johnson (1998).

\section{Partitioning of fault areas}

On the basis of the notion of the invasion of barriers introduced above, I re-estimate the fault areas of large to small interplate earthquakes along the San Andreas and near Japan for which slip distributions have been obtained by studies of near-field strong motion records. I divide each fault plane into asperities, invaded barriers, and un-invaded barriers as follows; Figure 5 schematically illustrates this partitioning.

Asperities are areas that have significant stress drops (see Bouchon (1997) for examples). I regard areas of significant slip, that are obtained by individual studies of rupture processes using strong motion records, as asperities.

Un-invaded barriers are areas that have aftershocks within the fault plane. These areas, which are often circumambient around the significant slip areas (Mendoza and Hartzell, 1988b), are interpreted as absorbing barriers having positive $a-b$, which are loaded at the time of the mainshock and gradually release the load partly as aftershocks. Note that conditionally stable areas with small negative $a-b$ are included within barriers and may produce aftershocks (Boatwright and Cocco, 1996).

Invaded barriers are areas that have neither significant slip or aftershocks. In this portion, due to the elevated pore fluid 


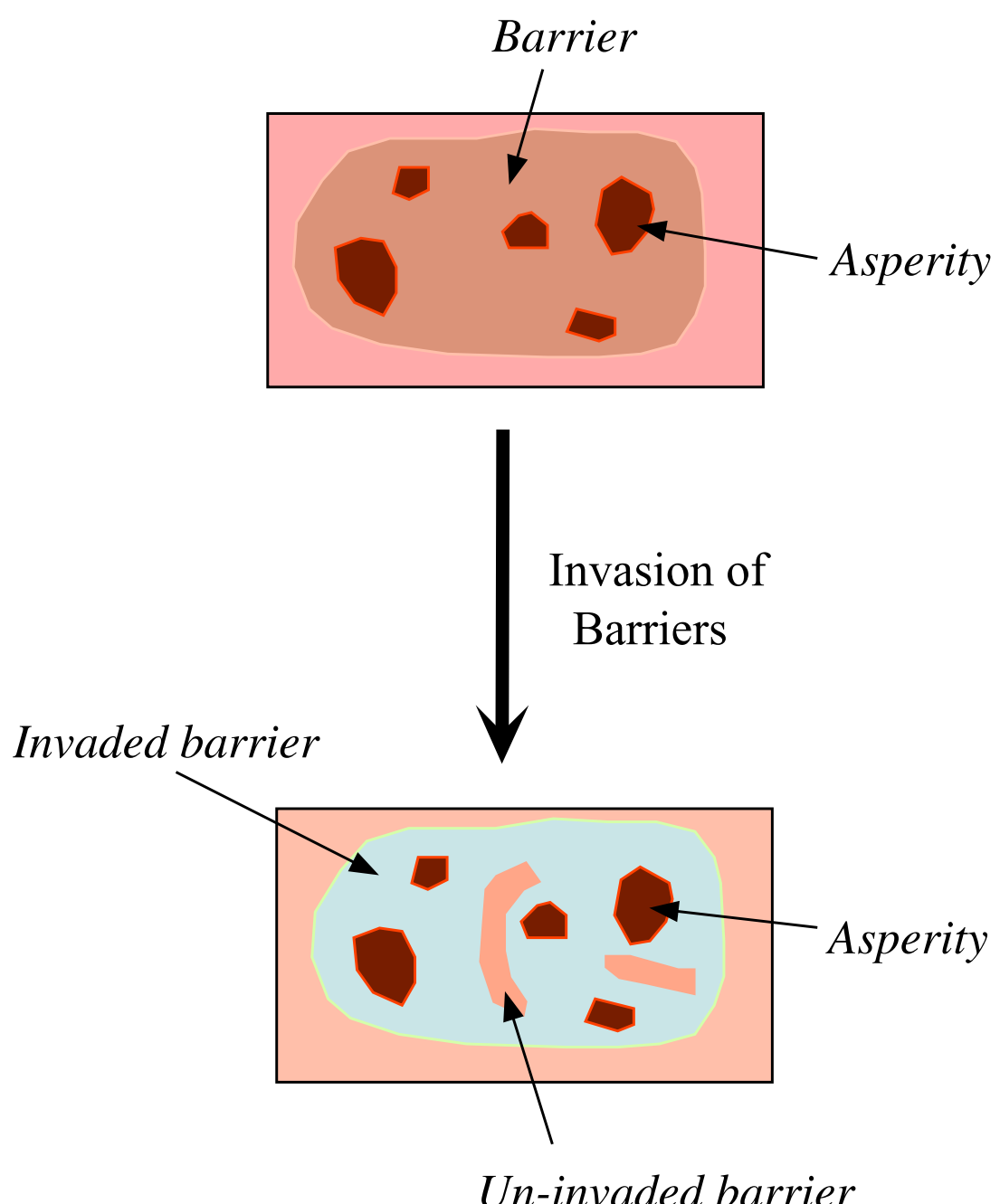

Fig. 5. Partitioning of a fault area into asperities, invaded barriers, and un-invaded barriers. The asperities are areas with a significant fault slip as revealed by analyses of strong motion records. The invaded barriers are areas without significant fault slip or aftershocks. The un-invaded barriers are areas where aftershocks occur within the fault plane.

pressure, the effective normal stress $\sigma_{n}^{*}$ and thus the friction $\mu \sigma_{n}^{*}$ are very small. They then exhibit unstable slip in association with loading at the time of the mainshock (Lockner and Byerlee, 1995). Although these areas may slip, they are characterized by low stress drops. In analyses of strong motion records, they appear to produce less accelerations. They lack aftershocks, however, because they are almost stress free.

To select only interplate events in the San Andreas, I pick up events along major traces of the San Andreas, and not those within the N. American or Pacific plates, such as the 1992 Landers and 1971 San Fernando earthquakes. Figure 6(a) shows the case of the 1984 Morgan Hill earthquake ( $M$ 6.2) in the San Andreas. The significant slip areas (Hartzell and Heaton, 1986) are darkly shaded and the inferred invaded barriers are lightly shaded or left blank. The aftershocks (Cockerham and Eaton, 1984) that represent un-invaded barriers are indicated by dots. In this case, the un-invaded barriers occupy a considerable fraction of the fault plane. The fault area, composed of asperities, invaded barriers, and un-invaded barriers in this case, is estimated to be $10 \mathrm{~km} \times 34 \mathrm{~km}$. Figure $6(\mathrm{~b})$ shows the case of the 1994 Sanriku-haruka-oki earthquake $\left(M_{w} 7.7\right)$ in the north- ern Honshu subduction zone. The significant slip areas (Nagai et al., 2001) are darkly shaded, the inferred invaded barriers are lightly shaded or left blank, and the aftershocks (Nagai et al., 2001) are indicated by triangles. The estimated fault area is $100 \mathrm{~km} \times 100 \mathrm{~km}$.

The fault areas are partitioned for the rest of the earthquakes listed in Table 1 and the estimated fault areas are listed in the same table.

\section{Relation of fault area and stress drop against seismic moment}

Stress drops are calculated for the events in Table 1 using the formulas according to the three different fault types (Kanamori and Anderson, 1975): (a) a rectangular fault with fault traces emergent at the surface, (b) a buried rectangular fault, and (c) a buried circular fault. Although stress drops for the earthquake mode are heterogeneous over the fault plane, the average slip is used to calculate the stress drop. Stress drops for $\mathrm{a}, \mathrm{b}$, and $\mathrm{c}$ types are

$$
\begin{aligned}
& \Delta \sigma=2 \pi \mu u / W, \\
& \Delta \sigma=4 \pi \mu u / W,
\end{aligned}
$$


(a)

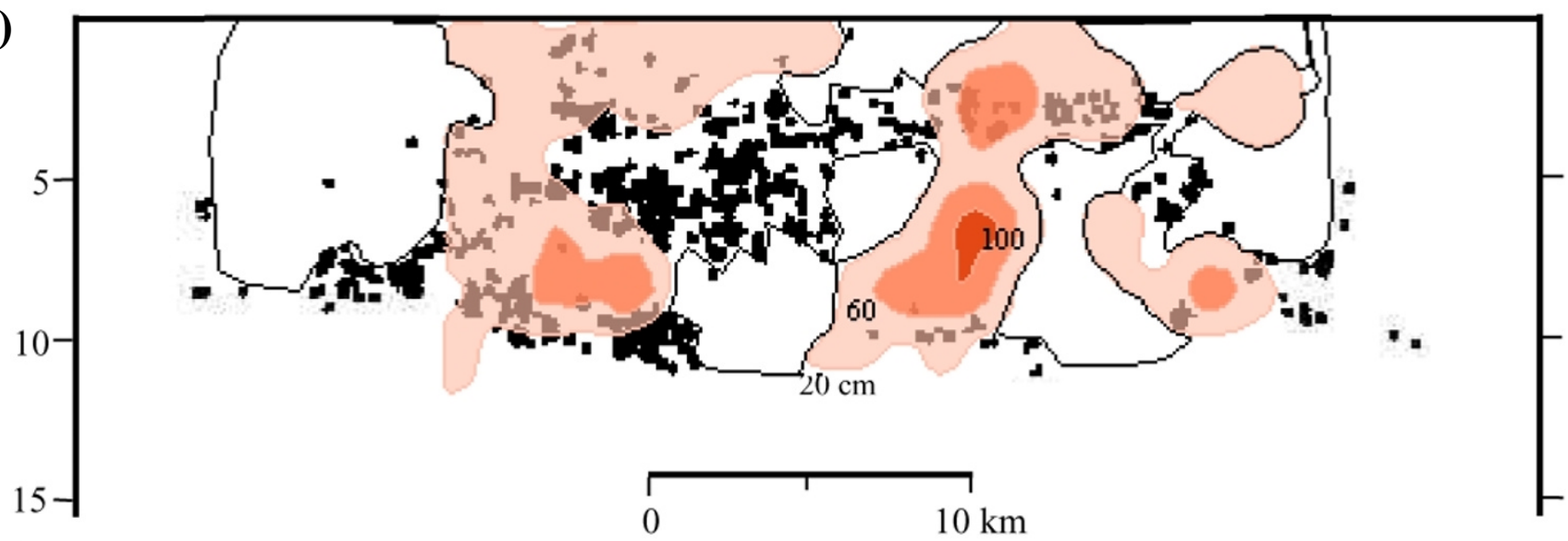

$\mathrm{km}$

(b)

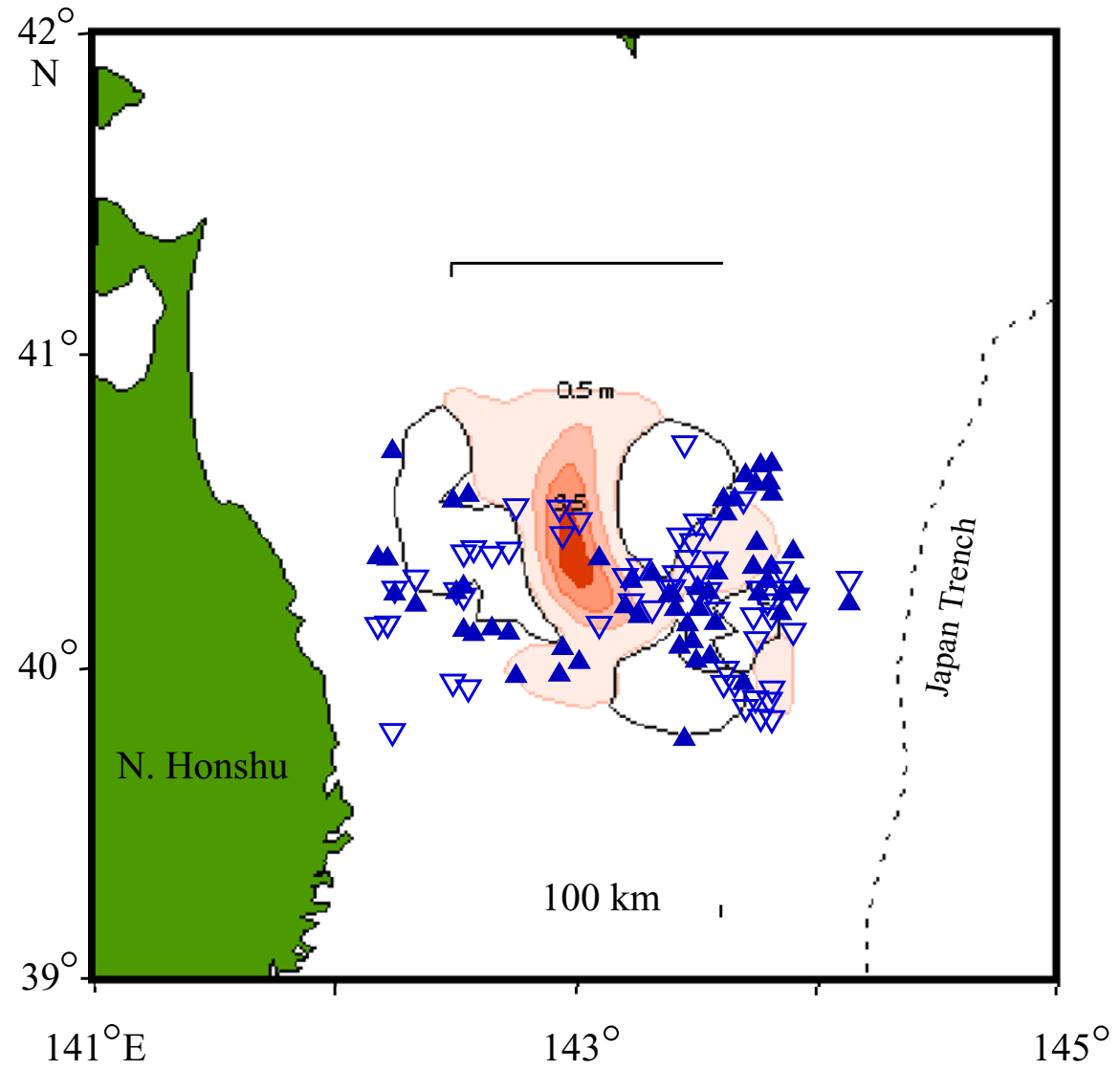

Fig. 6. (a) Partitioning of the fault area of the 1984 Morgan Hill earthquake (M 6.2) in the San Andreas. The areas of significant fault slip (Hartzell and Heaton, 1986) are darkly shaded and the inferred invaded barriers are lightly shaded or left blank. The aftershocks (Cockerham and Eaton, 1984) that represent un-invaded barriers are indicated by dots. (b) Partitioning of the fault area of the 1994 Sanriku-haruka-oki earthquake $\left(M_{w} 7.7\right)$ in the northern Honshu subduction zone. The areas of significant slip (Nagai et al., 2001) are darkly shaded, the inferred invaded barriers are lightly shaded or left blank, and the aftershocks (Nagai et al., 2001) are indicated by triangles.

and

$$
\Delta \sigma=(7 \pi / 16) \mu u / R
$$

respectively, where the value of $\mu$ is assumed to be $3 * 10^{10} \mathrm{~Pa}$, $W$ and $R$ are the width of a rectangular fault and the radius of a circular fault, respectively, and $u$ is calculated from $u=M_{o} /(\mu A)$ in which $M_{o}$ is from individual studies listed in Table 1 . The fault type and calculated stress drop of each event are listed in Table 1. The fault areas and the stress drops in Table 1 are plotted against the seismic moments in a logarithmic scale by the larger symbols in Figs. 7 and 8, respectively. Nadeau and Johnson (1998) estimated the fault areas of small to moderate-size repeating earthquakes in the San Andrea using the relation

$$
d M_{o} / d t=\mu(d u / d t) A,
$$

where $d M_{o} / d t$ is the seismic moment release rate calculated from the magnitude and the recurrence time, and $d u / d t$ is the average surface creeping rate in the section of the repeating earthquakes. Igarashi et al. (2003) applied the same method to two repeating earthquake sequences $(M \sim 4.8$ and $M \sim$ 
Table 1. List of interplate earthquakes analyzed.

\begin{tabular}{|c|c|c|c|c|c|c|c|c|}
\hline Event & Date & $M_{w}$ & Width & $(\mathrm{km})$ Length & $\log A / \mathrm{m}^{2}$ & $\begin{array}{r}\text { Fault } \\
\text { type }\end{array}$ & $\begin{array}{c}\Delta \sigma \\
(\mathrm{MPa})\end{array}$ & References \\
\hline \multicolumn{9}{|l|}{ San Andreas } \\
\hline Parkfield & $06 / 28 / 1966$ & 6.0 & 13 & 39 & 8.71 & $\mathrm{a}$ & 0.14 & Beroza [1989] \\
\hline CoyoteLake & 08/06/1979 & 5.6 & 6.3 & 6.3 & 7.60 & $\mathrm{c}$ & 3.38 & Liu \& Helmberger [1983] \\
\hline Morgan Hill & $04 / 24 / 1984$ & 6.1 & 10 & 34 & 8.53 & $\mathrm{~b}$ & 0.79 & Hartzell \& Heaton [1986] \\
\hline Parkfield * & $12 / 20 / 1994$ & 5.0 & 4.47 & 4.47 & 7.30 & $\mathrm{c}$ & 1.17 & Hellweg \& Boatwright [1999] \\
\hline Parkfield * & $11 / 14 / 1993$ & 4.8 & 0.95 & 0.95 & 5.95 & $\mathrm{c}$ & 52.73 & Hellweg \& Boatwright [1999] \\
\hline Imperial Valley & $11 / 15 / 1979$ & 6.4 & 10 & 48 & 8.68 & $\mathrm{a}$ & 0.66 & Hartzell \& Heaton [1983] \\
\hline Loma Prieta & $10 / 18 / 1989$ & 6.8 & 14 & 35 & 8.69 & $\mathrm{~b}$ & 4.27 & Beroza [1991] \\
\hline Superstition Hills & $11 / 24 / 1987$ & 6.4 & 10 & 20 & 8.30 & $\mathrm{~b}$ & 3.06 & Wald et al. [1990] \\
\hline North Palm Springs & 07/08/1986 & 6.1 & 10 & 22 & 8.34 & $\mathrm{~b}$ & 0.98 & Mendoza \& Hartzell [1988a] \\
\hline \multicolumn{9}{|l|}{ Japan } \\
\hline Tokachi-oki & 05/16/1968 & 8.3 & 106 & 200 & 10.33 & $\mathrm{~b}$ & 2.01 & Nagai et al. [2001] \\
\hline Haruka-oki & $12 / 28 / 1994$ & 7.7 & 150 & 100 & 10.18 & $\mathrm{c}$ & 0.59 & Nagai et al. [2001] \\
\hline Iwate-oki & $03 / 20 / 1960$ & 7.2 & 122 & 85 & 10.02 & $\mathrm{c}$ & 0.18 & Yamanaka \& Kikuchi [2001a] \\
\hline Iwate-oki & $11 / 02 / 1989$ & 7.0 & 70 & 100 & 9.85 & $\mathrm{c}$ & 0.17 & Yamanaka \& Kikuchi [2001a] \\
\hline Iwate-oki & 07/18/1992 & 6.6 & 53 & 50 & 9.42 & $\mathrm{c}$ & 0.18 & Yamanaka \& Kikuchi [2001a] \\
\hline Iwate-oki & $06 / 12 / 1968$ & 7.0 & 75 & 120 & 9.95 & $\mathrm{c}$ & 0.11 & Yamanaka \& Kikuchi [2001a] \\
\hline Miyagi-oki & $01 / 18 / 1981$ & 7.1 & 80 & 100 & 9.90 & $\mathrm{~b}$ & 0.11 & Yamanaka \& Kikuchi [2001a] \\
\hline Miyagi-oki & $06 / 12 / 1978$ & 7.5 & 80 & 100 & 9.90 & $\mathrm{c}$ & 0.76 & Yamanaka \& Kikuchi [2001a] \\
\hline Chichi & 09/20/1999 & 7.6 & 37 & 72 & 9.43 & $\mathrm{a}$ & 2.04 & Yagi and Kikuchi [2002] \\
\hline Tonankai & $12 / 07 / 1944$ & 7.9 & 95 & 150 & 10.24 & $\mathrm{a}$ & 0.29 & Kikuchi et al. [2003] \\
\hline Kanto & $09 / 01 / 1923$ & 7.9 & 66 & 120 & 9.90 & $\mathrm{a}$ & 1.09 & Wald \& Somerville [1995] \\
\hline Fukushima-oki & $02 / 25 / 2001$ & 5.9 & 8.5 & 14 & 8.08 & $\mathrm{~b}$ & 1.12 & Okada et al. [2001] \\
\hline Fukushima-oki & $02 / 26 / 2001$ & 5.5 & 4.6 & 5.1 & 7.37 & $\mathrm{~b}$ & 2.64 & Okada et al. [2001] \\
\hline Fukushima-oki & $02 / 06 / 1987$ & 6.7 & 14 & 21 & 8.47 & $\mathrm{~b}$ & 4.37 & Okada et al. [2001] \\
\hline Fukushima-oki & $04 / 07 / 1987$ & 6.6 & 13 & 18 & 8.37 & $\mathrm{~b}$ & 4.19 & Okada et al. [2001] \\
\hline Fukushima-oki & $04 / 23 / 1987$ & 6.5 & 10 & 14 & 8.15 & $\mathrm{~b}$ & 6.44 & Okada et al. [2001] \\
\hline Nankai & $12 / 20 / 1946$ & 8.2 & 150 & 310 & 10.67 & $\mathrm{a}$ & 0.23 & Yamanaka et al. [2001] \\
\hline
\end{tabular}

$M_{w}, A$, and $\Delta \sigma$ are moment magnitude, fault area, and stress drop, respectively. *Aftershock distribition is not available for these Parkfiled earthquakes, and I regard the slip area from strong motion analyses as the fault area. References are the sources for the fault slip distribution and $M_{o}$ from the analyses of strong motion records.

3.5) in the northern Honshu subduction zone and obtained their fault areas, assuming that the relative plate velocity equals $d u / d t$. Because $d u / d t$ in Eq. (15) is the displacement rate in the long term, it corresponds to the displacement rate associated with the slow failure scaled as Eqs. (1)-(6). The moment rate corresponding to this should thus be larger by a factor of $\lambda$ at most than the seismic moment rate (Eq. (10), Fig. 4).

To include the earthquakes in Nadeau and Johnson (1998) and Igarashi et al. (2003) in Figs. 7 and 8, I correct their fault areas by a factor of $\lambda$ from the reason stated above. I first estimate the value of $\lambda$. Regarding the two neighboring repeating earthquake sequences $(M \sim 4.8$ and $M \sim 3.5$ ) off northern Honshu as two successive order events, their fault areas (Igarashi et al., 2003) give $\lambda$ as 4.8. Then the fault areas of micro to small earthquakes in Nadeau and Johnson (1998) and Igarashi et al. (2003) are multiplied by $\lambda$ of this value assuming that they are degree $N_{a}$ events. Their stress drops are recalculated similarly using the corrected fault areas. These corrected values are plotted by the small symbols in Figs. 7 and 8.

The plot of $\log A$ versus $\log M_{o}$ in Fig. 7 has a linear trend with a slope of 0.83 , which is the value of the slope originally obtained for the micro to moderate repeating San Andreas earthquakes by Nadeau and Johnson (1998). The topmost line is the $\log A$ versus $\log M_{o}$ relation from equation (12) of Nadeau and Johnson (1998), but $A$ is multiplied by a factor of $\lambda$ as

$$
\begin{aligned}
\log A\left(\mathrm{~m}^{2}\right) & =0.83 \log M_{o}(\mathrm{Nm})-7.31+\log (\lambda) \\
& =0.83 \log M_{o}(\mathrm{Nm})-6.63 .
\end{aligned}
$$

The other broken and chain lines correspond to the theoretical relations between $\log A$ and $\log M_{o}$ for degree 1 earth- 


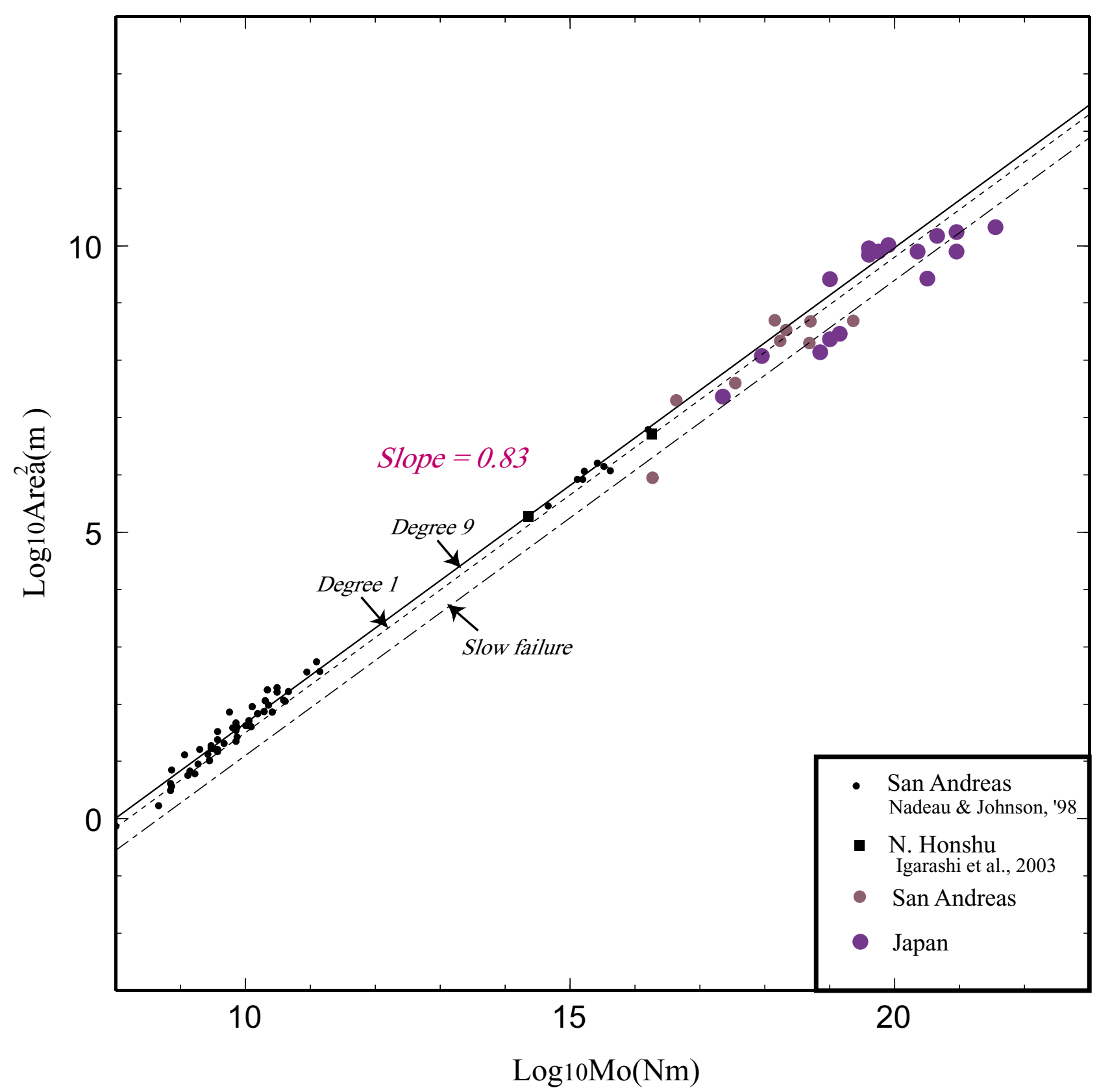

Fig. 7. Plot of $\log A$ versus $\log M_{o}$ for the earthquakes listed in Table 1 (larger symbols), and micro to small earthquakes in Nadeau and Johnson (1998) and Igarashi (2003) (smaller symbols). The fault areas for the latter are corrected by a factor of $\lambda$ for the difference between an earthquake and a slow failure (see text for details). The solid line was that obtained originally by Nadeau and Johnson (1998), with log $A$ corrected by adding log $\lambda$ in this study. The broken and chain lines are the theoretical relations between $\log A$ and $\log M_{o}$ for degree 1 earthquake and slow failure, respectively, when the topmost line is fixed for a degree 9 earthquake.

quakes and for slow failure, respectively, when the topmost line is fixed as the one for degree $N_{a}$ earthquakes. I use 9 as $N_{a}$, which is determined later.

The plot of $\log \Delta \sigma$ versus $\log M_{o}$ in Fig. 8 scatters more than those in Fig. 7, which is probably because of the different stress drop formulas for the various fault types. The lowermost line in Fig. 8 is derived from Eq. (16), assuming a circular fault geometry, and is represented as

$$
\log \Delta \sigma(\mathrm{MPa})=-0.25 \log M_{o}(\mathrm{Nm})+4.25 .
$$

The other broken and chain lines correspond to the theoretical relations between $\log \Delta \sigma$ and $\log M_{o}$ for degree 1 earthquakes and for slow failure, respectively, when the lower- most line is fixed as the one for degree $N_{a}$, i.e., degree 9 , earthquakes.

From the slope in Eq. (17), similarly to Sammis et al. (1999), I obtain

$$
\Delta \sigma \propto M_{o}^{-1 / 4}
$$

With Eq. (16), I obtain

$$
\Delta \sigma \propto A^{-0.3} .
$$

From the force balance and equating the stress drop with the strength as in Eq. (2), I obtain

$$
\Delta \sigma A=\Delta \sigma_{n \max } A_{n \max } N,
$$




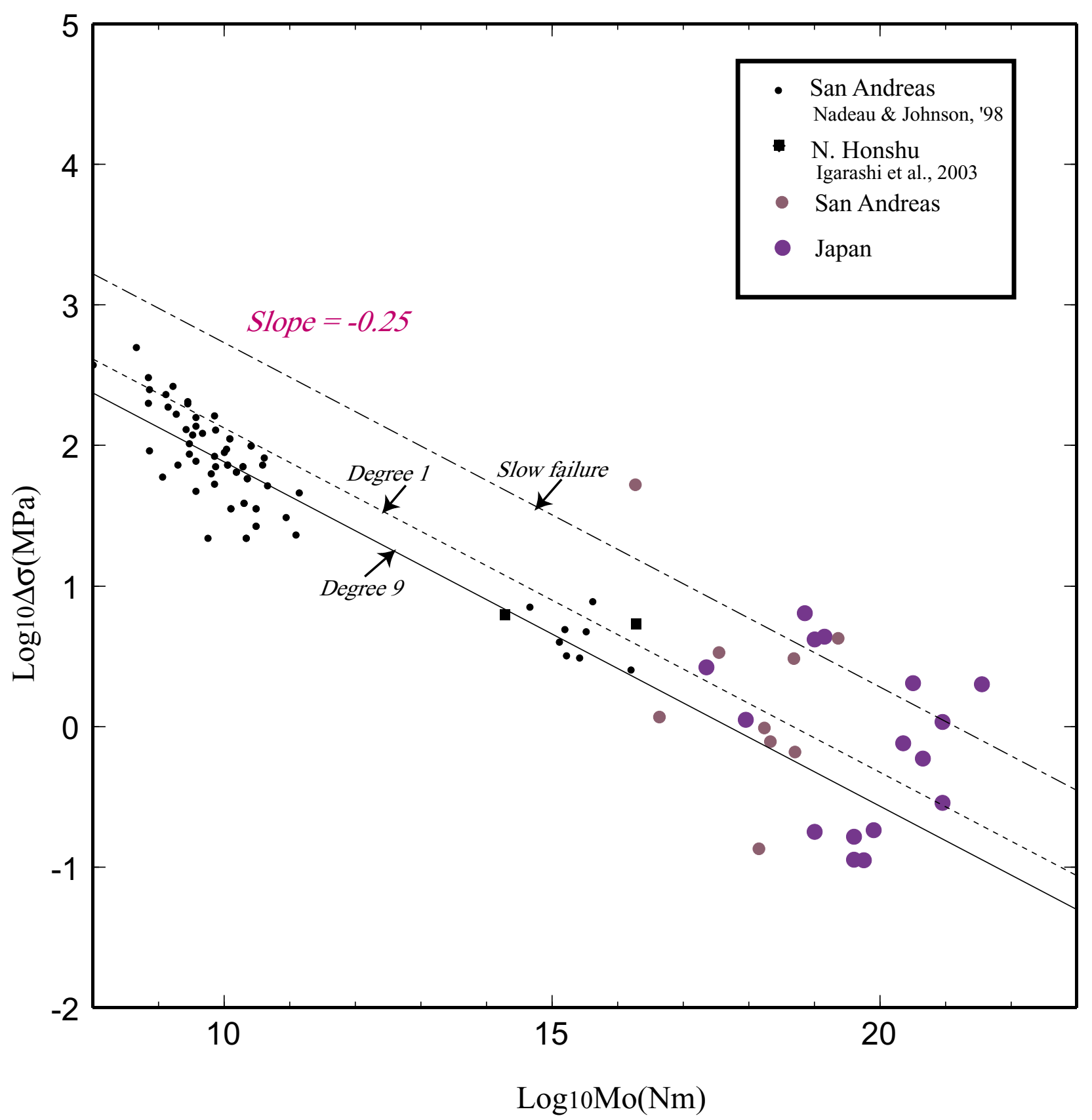

Fig. 8. Plot of $\log \Delta \sigma$ versus $\log M_{o}$ for the earthquakes listed in Table 1 (larger symbols), and micro to small earthquakes in Nadeau and Johnson (1998) and Igarashi (2003) (smaller symbols). The stress drops for the latter are corrected using the corrected fault areas. The solid line is that obtained originally by Nadeau and Johnson (1998), with $A$ in the stress drop calculation corrected by a factor of $\lambda$. The broken and chain lines are the theoretical relation between $\log \Delta \sigma$ and $\log M_{o}$ for degree 1 earthquake and slow failure, when the lowermost line is fixed for a degree 9 earthquake.

where $\Delta \sigma_{n \max }$ and $A_{n \max }$ are the stress drop and area of a unit asperity, respectively, and $N$ is the number of unit asperities within an order $n$ asperity. With Eq. (19), I obtain

$$
N \propto \Delta \sigma A=A^{0.7} \propto R^{1.4},
$$

where $R$ is the radius of an order $n$ asperity with area $A$. Because $N \propto R^{D}$ from Eq. (8), $D$ becomes 1.4. Using Eq. (9) and $\lambda$ of $4.8, N_{a}$ is determined to be 9 .

The fractal dimension obtained in this study differs from the value of 1.0 estimated for the San Andreas earthquakes by Sammis et al. (1999), who also used Eq. (18). The difference stems from the fact that Sammis et al. (1999) assumed an energy balance instead of Eq. (20), multiplying a displace- ment $u$ to this equation. There is, however, no guarantee that an energy balance holds, as shown by the relation of apparent stress versus seismic moment (Kanamori and Heaton, 2000; Izutani and Kanamori, 2001; Ide and Beroza, 2001).

In this study, the fractal dimension of asperities is determined by Eq. (19), and equivalently by Eq. (16) grossly. As stated in Johnson and Nadeau (2002), the fractal dimension may change from place to place locally, as the $b$-value changes. It would be also possible that in part of the San Andreas fault, the fractal dimension might be as small as 1.0, which is the value determined by Sammis et al. (1999). 


\section{(a) Asperity Type}

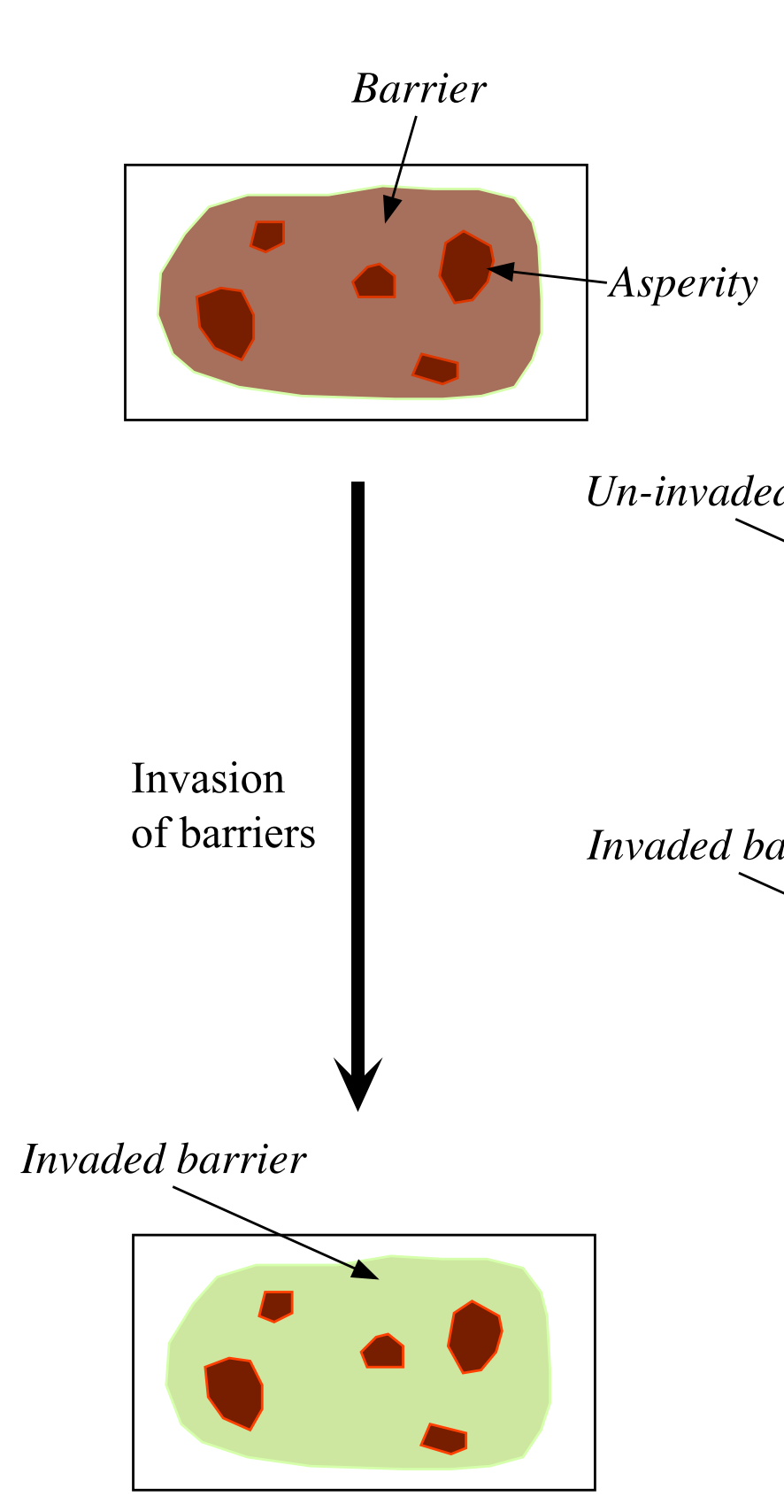

(b) Barrier Type
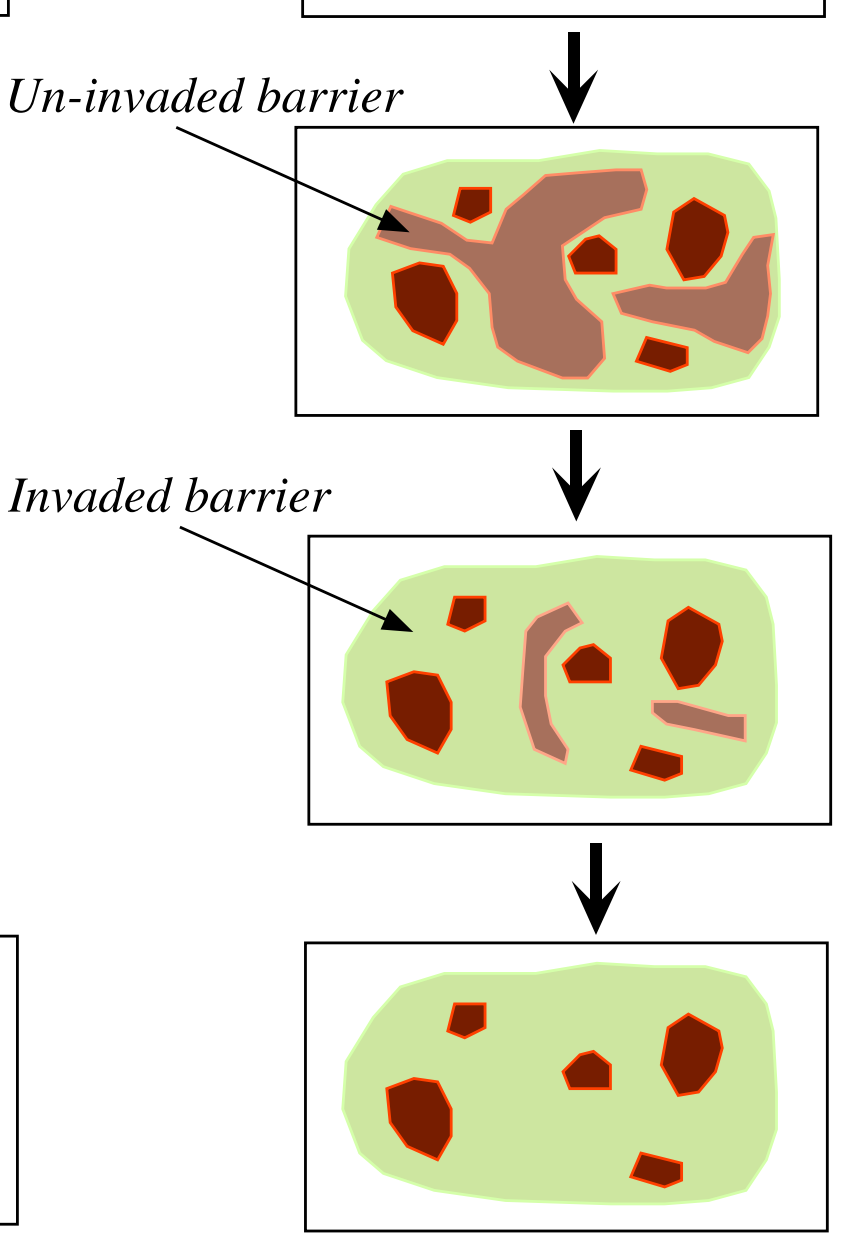

Fig. 9. Schematic illustration which explains the two types of earthquake families introduced by Aki (1984). (a) In the asperity type, invasion occurs smoothly and is completed before the next event. (b) In the barrier type, un-invaded barriers remain at the time of the next event and reduce the stress drop and thus the amplitude of the waveforms.

\section{Discussion}

6.1 Variations of seismic coupling along plate boundaries

There are often large variations in seismicity even within a short segment of a subduction zone where the same oceanic plate is subducting beneath the same overriding plate like the Japan Trench (Utsu, 1974; Kawakatsu and Seno, 1983). In the model presented here, given the fractal geometry of asperities being more or less uniform along plate boundaries, the variations in seismicity are explained by the difference in mode of invasion of barriers (Fig. 1(b)). In the extreme case that no invasion occurs, asperities break only in a slow failure mode and boundary faults creep. Although there would not be a perfectly creeping boundary, the Marianas and Bonins and the creeping section of the San Andreas might be close to such a boundary. If only a small barrier area is invaded as shown at the bottom of Fig. 1(b), only micro to small earthquakes occur in such fault zones. Instead, if a large area is invaded as shown at the top of Fig. 1(b), large earthquakes will occur. Therefore, even in a short segment of the boundary, it is possible to produce variations in seismicity depending on variations in the extent of invasion of barriers.

Because the present model regards earthquake size as being determined by the areal extent of invasion, it might turn 
into another enigma, i.e., how such variations in the extent of invasion occur. This is a subject to be explored in the future along with tests of the model against observations. The present model has, however, the merit that invaded barriers can be identified by negative polarity reflections in the seismic reflection profiles (Shipley et al., 1994; see also Seno, 2002), and repeated seismic reflection surveys might detect temporal changes in the reflection characteristics at the plate interface. The fact that strong reflections from the plate interface have recently been found at several different localities in the subduction zones near Japan looks promising (Ito et al., 2002; Fujie et al., 2002; Park et al., 2002; Kodaira et al., 2002).

\subsection{Earthquake families}

Hamaguchi and Hasegawa (1975) noted that similar earthquakes repeated in the aftershock sequence of the 1968 Tokachi-oki earthquake off northern Honshu, and introduced "earthquake families" to describe them. Aki (1984) identified two types of earthquake families, i.e., the asperity type and the barrier type, based on the work by Okada et al. (1981). In the asperity type, not only the waveforms but also the absolute amplitudes are similar. In the barrier type, waveforms, corner frequencies and high-frequency contents are similar, but amplitudes vary by more than one order of magnitude. Aki (1984) interpreted the former by repeated breakage of the same asperity within the same fault plane, and the latter by the barrier model of Das and Aki (1977), in which the high-frequency contents are controlled by strong barriers, but weak barriers are broken in different ways each time within the same fault plane.

Similar earthquakes (Geller and Mueller, 1980), repeating micro to small earthquakes along the San Andreas (Ellsworth and Dietz, 1990; Nadeau et al., 1995) and off northern Honshu (Igarashi et al., 2003; Matsuzawa et al., 2002), and large characteristic earthquakes in pertinent fault zones (Schwaltz and Coppersmith, 1984; Bakun and McEvilly, 1984; Wesnousky, 1994) might belong to earthquake families defined by Hamaguchi and Hasegawa (1975). I propose that an earthquake family results from the repetition of invasion of a pertinent region of barriers (Fig. 9). If invasion occurs smoothly and is completed in a time interval between two successive events (Fig. 9(a)), it would result in the asperity type. On the other hand, if un-invaded barriers remain at the time of the next event (Fig. 9(b)), this would result in the barrier type, because un-invaded barriers reduce the stress drop. On the other hand, high-frequency components might yet be the same because they are controlled by the geometry of asperities.

\subsection{Characteristic earthquakes versus the Gutenberg- Richter's law}

So far there has been debate on frequency versus size distribution of earthquakes as to whether characteristic earthquakes repeat or the Gutenberg-Richter's power law holds in particular fault zones (Wesnousky, 1994; Kagan, 1996). It is difficult to resolve this issue in a rigorous way because historical seismicity data are limited and results of analyses depend on the selection of study areas (Kagan, 1996). However, it is not denied that some parts of plate boundaries have been quasi-periodically ruptured by earthquakes as noted in the previous sub-section. For example, in the Nankai Trough off southwest Japan, great earthquakes $(M \sim 8)$ have repeated since 684 in a 100-200 year time interval (Ando, 1975) and the instrumentally-detected seismicity since the last event, i.e., the 1946 Nankai ( $M$ 8.0) earthquake, is very low in its rupture zone. The regular repetition of small to microearthquakes in the Parkfield area (Nadeau et al., 1995) and off northern Honshu (Igarashi et al., 2003; Matsuzawa et al., 2002) are other examples. On the other hand, there is no doubt that the Gutenberg-Richter's law holds if a large enough area is taken for statistics, such as the whole northern Honshu subduction zone.

I propose here that both reflect different aspects of the invasion of barriers. If asperities have a fractal distribution, their scale-invariance automatically implies power laws for frequency versus size distribution of earthquakes if the invasion of barriers occurs randomly. For example, assuming that any asperity has an equal chance of being broken, using Eq. (6) with $N_{a}=9$ and $\lambda=4.8$, and converting $M_{o}$ into magnitude, I obtain a $b$-value of 0.88 . This $b$-value happens to agree with that obtained for southern California earthquakes by Gutenberg and Richter (1944). The actual mode of invasion may vary from place to place. If fluids tend to invade smaller regions more frequently than larger ones, a larger $b$-value would result. On the other hand, if some particular regions are invaded in a regular manner due to some geophysical and/or geological reasons, characteristic earthquakes would result. Furthermore, if the mode of invasion is not eternal but is transient, the mode of earthquake occurrence might fluctuate between characteristic earthquakes and the Gutenberg-Richter's law.

\subsection{How strong are asperities?}

Sammis et al. (1999) addressed the question of how strong asperities are on the basis of the fractal distribution of asperities in the San Andreas derived from the scaling relations of Nadeau and Johnson (1998). Since that time, stress drops amounting to $2 \mathrm{GPa}$ for the smallest repeating earthquakes in the Parkfield area (Nadeau and Johnson, 1998) have been the most enigmatic problem, because they are apparently larger than the stress drops known for small to micro-earthquakes, and are even larger than the intact rock strength (Sammis and Rice, 2001; Sammis et al., 1999).

I show here that this problem might be resolved under the corrected scaling relations of Eqs. (16) and (17). Table 2 shows fault parameters, such as seismic moment, fault size, and amount of slip for degree 9 earthquake, and stress drops for degree 9 and degree 1 earthquakes and slow failure, ranging from order 0 to 8 . The seismic moment of degree 9 order 0 earthquake is fixed at $10^{21} \mathrm{Nm}\left(M_{w} 7.9\right)$. Let the smallest earthquake be degree 1 (if its degree is larger than one, there should be smaller earthquakes). From the earthquakes listed in Nadeau and Johnson (1998), the seismic moment of the smallest earthquakes is around $10^{8.5} \mathrm{Nm}$. From Table 2, this moment is realized at order 7 for a degree 1 earthquake. At this order, the stress drops of degree 9 and degree 1 earthquakes are 112 and $335 \mathrm{MPa}$, respectively (see also Fig. 8), which are on the same order as the strength estimated from the Coulomb-Navier failure criterion with the confining lithostatic pressure at a depth of $7 \mathrm{~km}$. These order 7 earthquakes are composed of order 8 asperities surrounded by invaded barriers (Fig. 3). The strength of the order 8 as- 
Table 2. Scaling of earthquake parameters versus order.

\begin{tabular}{|c|c|c|c|c|c|c|}
\hline \multirow{2}{*}{$N$} & \multirow{2}{*}{$\begin{array}{c}\log M o^{9} \\
(\mathrm{Nm})\end{array}$} & \multirow{2}{*}{$\begin{array}{c}R \\
(\mathrm{~km}) \\
\end{array}$} & \multirow{2}{*}{$\begin{array}{c}u \\
(\mathrm{~cm})\end{array}$} & $\Delta \sigma^{9}$ & $\Delta \sigma^{1}$ & $\Delta \sigma^{0}$ \\
\hline & & & & \multicolumn{3}{|c|}{$(\mathrm{MPa})$} \\
\hline 0 & 21.0 & 142 & 52.6 & 0.15 & 0.46 & 0.74 \\
\hline 1 & 19.4 & 29.6 & 28.1 & 0.4 & 1.2 & 1.9 \\
\hline 2 & 17.7 & 6.15 & 15.0 & 1.0 & 3.0 & 4.8 \\
\hline 3 & 16.1 & 1.28 & 8.0 & 2.6 & 7.7 & 12.4 \\
\hline 4 & 14.5 & 0.267 & 4.27 & 6.6 & 20 & 31.8 \\
\hline 5 & 12.8 & 0.0555 & 2.28 & 17.0 & 51 & 81.5 \\
\hline 6 & 11.1 & 0.0116 & 1.22 & 43.5 & 131 & 209 \\
\hline 7 & 9.5 & 0.0024 & 0.65 & 112 & 335 & 536 \\
\hline 8 & 7.9 & 0.0005 & 0.35 & 286 & 859 & 1375 \\
\hline
\end{tabular}

$N$ and $R$ are order and radius of an asperity, respectively, and $u$ is slip associated with slow failure.

$M o^{9}$ is the seismic moment of degree 9 earthquake. $\Delta \sigma^{9}, \Delta \sigma^{1}$, and $\Delta \sigma^{0}$ are the stress drops associated with

degree 9 earthquake, degree 1 earthquake, and slow failure, respectively.

perity is $1.4 \mathrm{GPa}$ from Table 2, which is the strength of the smallest unit asperity. This roughly coincides with the intact strength of $1033 \mathrm{MPa}$ and $1300 \mathrm{MPa}$ for Westerly granite estimated by Savage et al. (1996) from the analysis of internal friction and by Sammis et al. (1999) from the yield strength, respectively.

Letting $N_{a}$ be $7, \lambda$ and the strength of the unit asperity become 4.0 and $1.5 \mathrm{GPa}$, respectively. On the other hand, letting $N_{a}$ be 11 , they become 5.5 and $1.6 \mathrm{GPa}$, respectively. Though the estimation of $\lambda$ in the present study could have errors, it does not affect the fact that a unit asperity has strength close to that of the intact rock. The assumption of the model that only barriers are affected by pore fluid seems to be self-consistent because any asperity is composed of intact unit asperities, which would have low pore connectivity and not be greatly affected by pore fluid.

The stress drop becomes larger as the earthquake size becomes smaller in the scaling of the present study, which is demanded by the fractal distribution of asperities. This seems to violate the results of some previous seismological studies on small earthquakes, which show a tendency that stress drops become smaller as magnitudes become smaller (e.g., Abercrombie, 1995; Sacks and Rydelek, 1995). However, caution is needed when interpreting these stress drops of smaller earthquakes, because their sizes were often estimated by corner frequencies or pulse widths, and depend on assumed rupture velocities and attenuation structures. Furthermore, for a barrier-type earthquake family, the size is constant but the amplitude of seismic waves varies as the stress drop varies, which results in a positive correlation between the magnitude and the stress drop. This positive correlation of the barrier-type earthquake family is well demonstrated in figure 4 of Sacks and Rydelek (1995) who conducted a numerical simulation of earthquake generation assuming an earthquake quanta, i.e., a minimum unit of earthquake. It is interesting to note that the earthquakes in their figure show an opposite trend as a whole. Therefore, the scaling of the present study, and that of Nadeau and Johnson (1998), might not necessarily contradict the previous studies.

\subsection{Strong motions and hierarchy model}

Kikuchi (2000) tried to explain short-period components of observed seismograms based on the so-called hierarchy model of seismic sources (Fukao and Furumoto, 1985). The short-period components are derived from rupture of subfaults of successive lower hierarchies, with a self-similar geometry. Using the parameter notations in this study, $D=2$, $\lambda=3$, and $N_{a}=9$, in his model. Because $D=2$, no barrier portion appears and the stress drop is constant. It is clear that, using the scaling relations and parameter values in this study, short-period components can be similarly constructed by rupture of smaller (higher order) asperities, following Kikuchi (2000). Because of higher stress drops in the smaller asperities, short-period strong motions would be more effectively excited than Kikuchi's model. This may compensate the short-period components that are still deficient in his reconstruction (figures 7 and 9 of Kikuchi, 2000).

Because the fractal asperity model in this study includes hierarchy of sources of rupture, the facts cited as favoring the hierarchy model, such as the magnitude gaps between the mainshock and sub-events, and between the mainshock and the largest aftershocks, precursory slow rupture, the Gutenberg - Richter's law, and short-period strong motions (Fukao and Furumoto, 1985; Kikuchi, 2000) are also in favor of the present model; the last two were mentioned already. The values of $\lambda=4.8$, and $N_{a}=9$, and equation (6) gives the magnitude gap of 1.1 between order $n$ and order $n+1$ asperities. This is on the order of the observed gaps in magnitude between the mainshock and sub-events, and between the mainshock and the largest aftershock (Kikuchi, 2000). This gives some credence for the choice of $\lambda=4.8$ from the size ratio between the neighboring repeating earthquakes off northern Honshu. If this is the size ratio between $n$ and $n+2$ order asperities, $\lambda=2.2$ and $N_{a}=3$, which gives the magnitude gap of 0.55 . If this is the size ratio between $n$ and 
$n+3$ order asperities, $\lambda=1.7$ and $N_{a}=2$, which gives the magnitude gap of 0.35 ; both are smaller than the observed gaps.

The present model, however, can have a greater diversity in rupture characteristics of seismic sources than the hierarchy model, because barriers are contained inside of an asperity, and the extent of invasion of the barriers affect rupture mode of smaller asperities. The short-period strong motions will not be generated efficiently when the barriers are not invaded. Appearance of the precursory slow phase of incipient rupture may also be dependent on the extent of invasion, if it represents seismic rupture of smaller asperities.

\section{Conclusions}

I present a model to explain variations of seismicity along plate boundaries. The basic assumptions of the model are: (1) a plate boundary fault zone consists of asperities and barriers, (2) asperities are distributed in a fractal manner, (3) pore fluid pressure can be elevated almost to the lithostatic pressure only in barriers, and (4) only the region whose barriers are invaded can rupture as an earthquake when asperities inside break. Assuming a circular shape for an asperity, fault parameters such as fault area, stress drop, slip, and moment are scaled against the sizes of asperities. Earthquakes, which have multiple local stress drops, are scaled in a similar manner.

I partition a fault area of an interplate earthquake into asperities, invaded barriers, and un-invaded barriers, and apply it to the interplate earthquakes in the San Andreas and in the subduction zones near Japan, to re-estimate their fault areas. The plot of the re-estimated fault areas versus the seismic moments, along with the corrected values in Nadeau and Johnson (1998) and Igarashi et al. (2003), determines the fractal dimension of asperities to be 1.4, and nine smaller asperities, whose radius is $1 / 4.8$ of the larger one, are contained in the larger one. This scaling gives the stress drop of the smallest repeating earthquakes in the San Andreas and the strength of the unit asperities inside them as $340 \mathrm{MPa}$ and 1.4 GPa, respectively, which are consistent with rock fracture experiments.

The present model explains various features of seismicity along plate boundaries by a combination of invasion of barriers and fractal distribution of asperities. If the invaded barrier region is small (large), a small (large) earthquake would result. Thus, even within a short segment of the boundary, it is possible to produce a variety of modes of seismicity. The scale-invariance of fractal asperities leads to power laws such as the Gutenberg - Richter's law, if invasion of barriers occurs in a random manner over the region considered. In contrast, if a particular region is invaded repeatedly in a regular manner, this would result in characteristic repeating earthquakes. The model should be tested in the future against various observations. In particular, temporal monitoring of reflection characteristics at the plate interface by repeated 3$\mathrm{D}$ seismic reflection surveys would be promising for testing the notion of invasion of barriers.

Acknowledgments. I thank Lane Johnson and an anonymous reviewer for their critial review of the manuscript. I thank Toshihiro Igarashi, Yoshiko Yamanaka, Toru Matsuzawa, Aki Ito, Akira
Hasegawa, Tomomi Okada, Naoshi Hirata, and Masayuki Kikuchi for providing their preprints, data, and unpublished figures. I also thank Masao Nakatani, Yasuo Izutani, Yasumaro Kakehi, Kiyohiko Yamamoto, and Toru Matsuzawa for useful discussions.

\section{References}

Abercrombie, R. E., Earthquake source scaling relationships from -1 to 5 $M_{L}$ using seismograms recorded at 2.5-km depth, J. Geophys. Res., 100, 24015-24036, 1995.

Aki, K., Characterization of barriers on an earthquake fault, J. Geophys. Res., 84, 6140-6148, 1979.

Aki, K., Asperities, barriers, characteristic earthquakes and strong motion prediction, J. Geophys. Res., 89, 5867-5872, 1984.

Ando, M., Source mechanisms and tectonic significance of historical earthquakes along the Nankai Trough, Japan, Tectonophysics, 27, 119-140, 1975.

Atwater, B. F. and E. Hemphill-Haley, Recurrence Interval for Great Earthquakes of the Past 3,500 Years at Northeastern Willapa Bay, Washington, U. S. Geol. Survey Prof. Paper 1576, 108 pp., 1997.

Bakun, W. H. and T. V. McEvilly, Recurrence models and Parkfield, California, earthquakes, J. Geophys. Res., 89, 3051-3058, 1984.

Beroza, G., Near-source imaging of seismic rupture, Ph.D. thesis, Mass. Inst. of Technol., Cambridge, 1989.

Beroza, G. C., Near-source modeling of the Loma Prieta earthquake: Evidence for heterogeneous slip and implications for earthquake hazard, Bull. Seism. Soc. Am., 81, 1603-1621, 1991.

Blanpied, M. L., D. A. Lockner, and J. D. Byerlee, An earthquake mechanism based on rapid sealing of faults, Nature, 358, 574-576, 1992.

Boatwright, J. and M. Cocco, Frictional constraints on crustal faulting, $J$. Geophys. Res., 101, 13895-13909, 1996.

Bouchon, M., The state of stress on some faluts of the San Andreas system as inferred from near-field strong motion data, J. Geophys. Res., 102 11731-11744, 1997.

Byerlee, J., Model for episodic flow of high-pressure water in fault zones before earthquakes, Geology, 21, 303-306, 1993.

Cloos, M., Thrust-type subduction-zone earthquakes and seamount asperities: a physical model for seismic rupture, Geology, 20, 601-604, 1992.

Cockerham, R. S. and J. P. Eaton, The April 24, 1984 Morgan Hill earthquake and its aftershocks: April 24 through September 30, 1984, in The 1984 Morgan Hill, California Earthquake, CDMG Special Publication, 68, 1984.

Das, S. and K. Aki, Fault plane with barriers: A versatile earthquake model, J. Geophys. Res., 82, 5658-5670, 1977.

Dieterich, J. H., Modeling of rock friction 1. Experimental results and constitutive equations, J. Geophys. Res., 84, 2161-2168, 1979.

Dieterich, J. H. and B. D. Kilgore, Imaging surface contacts: power law contact distributions and contact stresses in quartz, calcite, glass and acrylic plastic, Tectonophysics, 256, 219-239, 1996.

Ellsworth, W. L. and L. D. Dietz, Repeating earthquakes: Characteristics and implications, U.S. Geol. Surv. Open File Rep., 90-98, 226-245, 1990.

Fleitout, L., The sources of lithospheric tectonic stresses, Phil. Trans. R. soc. Lond. A, 337, 73-81, 1991 .

Fujie, T., J. Kasahara, R. Hino, T. Sato, M. Shinohara, and K. Suyehiro, A significant relation between seismic activities and reflection intensities in the Japan Trench region, Geophys. Res. Lett., 29(7), doi:10.1029/20001GL013764, 2002.

Fukao, Y. and M. Furumoto, Hierarchy in earthquake size distribution, Phys. Earth Planet. Inter., 37, 149-168, 1985.

Geller, R. J. and C. S. Mueller, Four similar earthquakes in central California, Geophys. Res. Lett., 7, 821-824, 1980.

Gutenberg, B. and C. F. Richter, Frequency of earthquakes in California, Bull. Seism. Soc. Am., 34, 185-188, 1944.

Hamaguchi, H. and A. Hasegawa, Recurrent occurrence of the earthquakes with similar wave forms and its related problems, Jisin, 28, 153-169, 1975 (in Japanese).

Hartzell, S. H. and T. H. Heaton, Rupture history of the 1984 Morgan Hill, California, earthquake from the inversion of strong motion records, Bull. Seism. Soc. Am., 76, 649-674, 1986.

Hartzell, S. H. and T. H. Heaton, Inversion of strong ground motion and teleseismic waveform data for the fault rupture history of the 1979 Imperial Valley, California, earthquake, Bull. Seism. Soc. Am., 73, 1553-1583, 1983.

Hellweg, M. and J. Boatwright, Mapping the rupture process of moderate earthquakes by inverting accelerograms, J. Geophys. Res., 104, 7319- 
7328,1999

Hickman, S., R. Sibson, and R. Bruhn, Introduction to special section: mechanical involvement of fluids in faulting, J. Geophys. Res., 100, 1283112840, 1995.

Hubbert, M. K. and W. W. Rubey, Role of fluid pressure in mechanics of overthrust faulting 1. Mechanics of fluid-filled porous solids and its application to overthrust faulting, Bull. Geol. Soc. Am., 70, 115-166, 1959.

Hurukawa, N. and M. Imoto, Subducting oceanic crusts of the Philippine Sea and Pacific plates and weak-zone-normal compression in the Kanto district, Japan, Geophys. J. Int., 109, 639-652, 1992.

Hyndman, R. D., M. Yamano, and D. A. Oleskevich, The seismogenic zone of subduction thrust faults, The Island Arc, 6, 244-260, 1997.

Ide, S. and G. C. Beroza, Does apparent stress vary with earthquake size?, Geophys. Res. Lett., 28, 3349-3352, 2001.

Igarashi, T., T. Matsuzawa, and A. Hasegawa, Repeating earthquakes and interplate aseismic slip in the northeastern Japan subduction zone, $J$ Geophys. Res., 108(B5), doi:10.1029/2002JB001920, 2003.

Irwin, W. P. and I. Barnes, Effect of geologic structure and metamorphic fluids on seismic behavior of the San Andreas fault system in central and northern California, Geology, 3, 713-716, 1975.

Ito, A., R. Hino, M. Nishino, H. Fujimoto, S. Miura, S. Kodaira, and A. Hasemi, Deep crustal structure of the northeastern Japan fore arc by a seismic exploration, Jisin, 54, 507-520, 2002 (in Japanese).

Izutani, Y. and H. Kanamori, Scale-dependence of seismic energy-tomoment ratio for strike-slip earthquakes in Japan, Geophys. Res. Lett. 28, 4007-4010, 2001.

Johnson, P. A. and T. V. McEvilly, Parkfield seismicity: Fluid-driven?, J. Geophys. Res., 100, 12937-12950, 1995.

Johnson, L. R. and R. M. Nadeau, Asperity model of an earthquake: Static problem, Bull. Seism. Soc. Am., 92, 672-686, 2002.

Kagan, Y. Y., Comments on "The Gutenberg-Richter or characteristic earthquake distribution, which is it?” by Steven G. Wesnousky, Bull. Seism Soc. Am., 86, 274-285, 1996.

Kanamori, H., Rupture process of subduction-zone earthquakes, Ann. Rev Earth. Planet. Sci., 14, 293-322, 1986.

Kanamori, H. and D. L. Anderson, Theoretical basis of some empirica relations in seismology, Bull. Seism. Soc. Am., 65, 1073-1095, 1975.

Kanamori, H. and T. H. Heaton, Microscopic and macroscopic physics of earthquakes, in Geocomplexity and the Physics of Earthquakes, Geophys. Monogr., AGU, 120, 147-163, 2000.

Kato, N. and T. Hirasawa, A model for possible crustal deformation prior to a coming large interplate earthquake in the Tokai district, central Japan, Bull. Seism. Soc. Am., 89, 1401-1417, 1999.

Kawakatsu, H. and T. Seno, Triple seismic zone and the regional variation of seismicity along the northern Honshu arc, J. Geophys. Res., 88, 42154230, 1983.

Kikuchi, M., A hierarchy model of earthquake sources, Mem. Proc. Intern. Symp. on Earthquake Disaster Prevention, CENAPRED, JICA, IDNDR 1, 170-177, 2000.

Kikuchi, M., M. Nakamura, and K. Yoshikawa, Source rupture processes of the 1944 Tonankai earthquake and the 1945 Mikawa earthquake derived from low-gain seismograms, Earth Planets Space, 55, 159-172, 2003.

Kodaira, S., E. Kurashimo, N. Takahashi, A. Nakanishi, S. Miura, J.-O Park, T. Iwasaki, N. Hirata, K. Ito, and Y. Kaneda, Structural factors in controlling a rupture process of a magathrust earthquake at the Nanka trough seismogenic zone: results from an onshore-offshore seismic study, Geophys. J. Inter., 149, 815-835, 2002.

Kostoglodov, V. and L. Ponce, Relationship between subduction and seismicity in the Mexican part of the Middle America trench, J. Geophys. Res., 99, 729-742, 1994

Lachenbruch, A. H. and J. H. Sass, Heat flow from Cajon Pass, fault strength, and tectonic implications, J. Geophys. Res., 97, 4995-5015, 1992.

Lay, T. and H. Kanamori, An asperity model of large earthquake sequences, in Earthquake Prediction, an International Review, edited by D. Simpson and P. Richard, Maurice Ewing Series, 4, AGU, Washington, D.C. pp. 579-592, 1981

Lay, T., H. Kanamori, and L. Ruff, The asperity model and the nature of large subduction zone earthquakes, Earthquake Pred. Res., 1, 3-71, 1982.

Liu, H.-L. and D. V. Helmberger, The near-source ground motion of the 6 August 1979 Coyote Lake, California, earthquake, Bull. Seism. Soc. Am. 73, 201-218, 1983 .

Lockner, D. A. and J. D. Byerlee, An earthquake instability model based on faults containing high fluid-pressure compartments, $P A G E O P H, \mathbf{1 4 5}$
717-745, 1995.

Magee, M. E. and M. D. Zoback, Evidence for a weak interplate thrust fault along the northern Japan subduction zone and implications for the mechanics of thrust faulting and fluid expulsion, Geology, 21, 809-812, 1993.

Mareschal, J.-C., Fractal reconstruction of sea-floor topography, $P A$ GEOPH, 131, 197-210, 1989.

Matsuzawa, T., T. Igarashi, and A. Hasegawa, Characteristic smallearthquake sequence off Sanriku, northeastern Honshu, Japan, Geophys. Res. Lett., 29(11), doi: 10.1029/200GL014632, 2002.

Mendoza, C. and S. H. Hartzell, Inversion for slip distribution using teleseismic P waveforms: North Palm Springs, Borah Peak, and Michoacan earthquake, Bull. Seism. Soc. Am., 78, 1092-1111, 1988a.

Mendoza, C. and S. H. Hartzell, Aftershock patterns and main shock faulting, Bull. Seism. Soc. Am., 78, 1438-1449, 1988b

Mount, V. S. and J. Suppe, State of stress near the San Andreas fault: Implications for wrench tectonics, Geology, 15, 1143-1146, 1987.

Nadeau, R. M. and L. R. Johnson, Seismological studies at Parkfield VI: Moment release rates and estimates of source parameters for small repeating earthquakes, Bull. Seism. Soc. Am., 88, 790-814, 1998.

Nadeau, R. M., W. Foxall, and T. V. McEvilly, Clustering and periodic recurrence of microearthquakes on the San Andreas fault at Parkfield California, Science, 267, 503-507, 1995.

Nagai, R., M. Kikuchi, and Y. Yamanaka, Comparative study on the source processes of recurrent large earthquakes in Sanriku-oki Region: the 1968 Tokachi-oki earthquake and the 1994 Sanriku-oki earthquake, Jisin, 54 267-280, 2001 (in Japanese).

Okada, H., H. Watanabe, H. Yamashita, and I. Yokoyama, Seismological significance of the 1977-1978 eruptions and the magma intrusion process of Usu volcano, Hokkaido, J. Volcanol. Geotherm. Res., 9, 311-334, 1981.

Okada, T., T. Yamashita, A. Hasegawa, J. Koike, and S. Takahama, Source process of M5.8 earthquake off Fukushima in 2001, Abstr. Seismol. Soc. Jpn, C68, 2001 (in Japanese).

Oleskevich, D. A., R. D. Hyndman, and K. Wang, The updip and downdip limits to great subduction earthquakes: thermal and strucural models of Cascadia, south Alaska, SW Japan, and Chile, J. Geophys. Res., 104, 14965-14991, 1999.

Pacheco, J. F., L. R. Sykes, and C. H. Scholz, Nature of seismic coupling along simple plate boundaries of the subduction type, J. Geophys. Res. 98, 14133-14159, 1993.

Park, J.-O., T. Tsuru, N. Takahashi, T. Hori, S. Kodaira, A. Nakanishi, S. Miura, and Y. Kaneda, A deep strong reflector in the Nankai accretionary wedge from multichannel seismic data: Implications for underplating and interseismic shear stress release, J. Geophys. Res., 107(B4) doi:10/1029/2001JB000262, 2002.

Parsons, B. and F. M. Richter, A relation between the driving force and geoid anomaly associated with mid-oceanic ridges, Earth Planet. Sci. Lett., 51, 445-450, 1980.

Peterson, E. T. and T. Seno, Factors affecting seismic moment release rates in subduction zones, J. Geophys. Res., 89, 10233-10248, 1984.

Rice, J. R., Fault stress states, pore pressure distributions, and the weakness of the San Andreas fault, in Fault Mechanics and Transport Propoerties of Rocks, edited by B. Evans and T. F. Wong, Academic Press, London, 476-503, 1992.

Ruff, L. J., Do trench sediments affect great earthquake occurrence in subduction zones?, PAGEOPH, 129, 263-282, 1989.

Ruff, L. and H. Kanamori, Seismicity and the subduction process, Phys. Earth Planet. Inter. 23, 240-252, 1980.

Ruina, A., Slip instability and state variable friction laws, J. Geophys. Res., 88, 10359-10370, 1983

Sacks, I. S. and P. A. Rydelek, Earthquake "Quanta" as an explanation for observed magnitudes and stress drops, Bull. Seism. Soc. Am., 85, 808813,1995

Sammis, C. G. and J. R. Rice, Repeating earthquakes as low-stress-drop events at a border between locked and creeping fault patches, Bull. Seism Soc. Am., 91, 532-537, 2001

Sammis, C. G., R. M. Nadeau, and L. R. Johnson, How strong is an asperity?, J. Geophys. Res., 104, 10609-10619, 1999.

Savage, J. C., J. D. Byerlee, and D. A. Lockner, Is internal friction friction? Geophys. Res. Lett., 23, 487-490, 1996.

Scholz, C. H., The Mechanics of Earthquakes and Faulting, Cambridge Univ. Press, 439 pp., 1990.

Scholz, C. H. and J. Campos, On the mechanism of seismic decoupling and back arc spreading at subduction zones, J. Geophys. Res., 100, 22103 
22115, 1995.

Scholz, C. H., M. Wyss, and S. W. Smith, Seismic and aseismic slip on the San Andreas fault, J. Geophys. Res., 74, 2049-2069, 1969.

Schwaltz, D. P. and K. J. Coppersmith, Fault behavior and characteristic earthquakes: Examples from the Wasatch and San Andreas fault zones, $J$. Geophys. Res., 89, 5681-5698, 1984.

Segall, P. and J. R. Rice, Dilatancy, compaction, and slip instability of a fluid-infiltrated fault, J. Geophys. Res., 100, 22155-22171, 1995.

Seno, T., Tsunami earthquakes as transient phenomena, Geophys. Res. Lett., 29(10), doi: 10.1029/2002GL014868, 2002.

Seno, T. and T. Eguchi, Seismotectonics of the western Pacific region, in Tectonics of the Western Pacific-Indonesian Region, edited by S. Uyeda and T. W. C. Hilde, Geodynamics Series, GSA/AGU, Washington D.C., 11, 5-40, 1983.

Seno, T., T. Sakurai, and S. Stein, Can the Okhotsk plate be discriminated from the North American plate?, J. Geophys. Res., 101, 11305-11315, 1996.

Shimamoto, T., T. Seno, and S. Uyeda, Rheological framework for comparative subductology, in Relating Geophysical Structures and Processes: The Jeffreys Volume, Geophys. Monogr., edited by K. Aki and R. Dmowska, IUGG/AGU, 76, 39-52, 1993.

Shipley, T. H., G. F. Moore, N. L. Bang, J. C. Moore, and P. L. Stoffa, Seismically inferred dilatancy distribution, northern Barbados Ridge decollement: Implications of fluid migration and fault strength, Geology, 22, 411-414, 1994.

Sibson, R. H., Fluid flow accompanying faulting: Field evidence and models, in Earthquake Prediction, Maurice Ewing Series, AGU, 4, 593-603, 1981.

Sibson, R. H., Implications of fault-value behaviour for rupture nucleation and recurrence, Tectonophysics, 211, 283-893, 1992.

Sleep, N. H., Ductile creep, compaction, and rate and state dependent friction within major fault zones, J. Geophys. Res., 100, 13065-13080, 1995

Sleep, N. H. and M. L. Blanpied, Creep, compaction and the weak rheology of major faults, Nature, 359, 687-692, 1992.

Tobin, H. J., J. C. Moore, and G. F. Moore, Fluid pressure in the frontal thrust of the Oregon accretionary prism: Experimental constraints, Geology, 22, 979-982, 1994.

Tse, S. T. and J. R. Rice, Crustal earthquake instability in relation to the depth variation of frictional slip properties, J. Geophys. Res., 91, 94529472, 1986.

Turcotte, D. L., Fractals in geology and geophysics, PAGEOPH, 131, 171196, 1989

Utsu, T., Space-time pattern of large earthquakes occurring off the Pacific coast of the Japanese islands, J. Phys. Earth, 22, 325-342, 1974

Uyeda, S. and H. Kanamori, Back-arc opening and the mode of subduction, J. Geophys. Res., 84, 1049-1061, 1979.

Wald, D. J., D. V. Helmberger, and S. H. Hartzell, Rupture process of the 1987 Superstition Hills earthquake from the inversion of strong-motion data, Bull. Seism. Soc. Am., 80, 1079-1098, 1990.

Wald, D. J. and P. G. Somerville, Variable-slip rupture model of the great 1923 Kanto, Japan, earthquake: Geodetic and body-waveform analysis, Bull. Seism. Soc. Am., 85, 159-177, 1995.

Wallace, R. E., Earthquake recurrence intervals on the San Andreas fault, Geol. Soc. Am. Bull., 81, 2875-2890, 1970.

Wesnousky, S. G., The Gutenberg-Richter or characteristic earthquake distribution, which is it?, Bull. Seism. Soc. Am., 84, 1940-1959, 1994.

Wiens, D. A. and S. Stein, Implications of oceanic intraplate seismicity for plate stresses, driving forces and rheology, Tectonophysics, 116, 143 162,1985

Yagi, Y. and M. Kikuchi, Source process of the Chi-Chi, Taiwan earthquake of Sept. 21, 1999, 2002 (in preparation).

Yamanaka, Y. and M. Kikuchi, Asperity map along the subduction zone in northeastern Japan inferred from regional seismic data, J. Geophys. Res., 2003 (submitted).

Yamanaka, Y., M. Kikuchi, and K. Yoshikawa, Source processes of the 1946 Nankai earthquake (M 8.0) and the 1964 Niigata earthquake (M 7.5) inferred from JMA strong motion records, Abstr. Seism. Soc. Jpn, C68, 2001 (in Japanese).

Zoback, M. D., M. L. Zoback, V. S. Mount, J. Suppe, J. P. Eaton, J. H. Healy, D. Oppenheimer, P. Reasenberg, L. Jones, C. B. Raleigh, I. G. Wong, O. Scotti, and C. Wentworth, New evidence on the state of stress of the San Andreas fault system, Science, 238, 1105-1111, 1987.

T. Seno (e-mail: seno@eri.u-tokyo.ac.jp) 